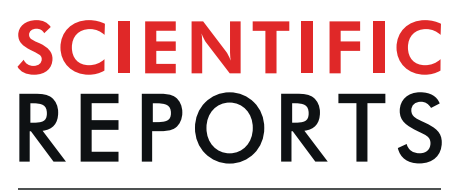

natureresearch

\title{
Novel allelic variation in the Phospholipase D alpha1 gene (OsPLD $\alpha 1$ ) of wild Oryza species implies to its low expression in rice bran
}

\author{
Amandeep Kaur ${ }^{1,2}$, Kumari Neelam $^{1}$, Karminderbir Kaur ${ }^{1}$, Ai Kitazumi ${ }^{2,3}$, Benildo G. de los \\ Reyes $^{2,3}$ \& Kuldeep Singh ${ }^{1,4^{*}}$
}

Rice bran, a by-product after milling, is a rich source of phytonutrients like oryzanols, tocopherols, tocotrienols, phytosterols, and dietary fibers. Moreover, exceptional properties of the rice bran oil make it unparalleled to other vegetable oils. However, a lipolytic enzyme Phospholipase D alpha1 (OsPLDo1) causes rancidity and 'stale flavor' in the oil, and thus limits the rice bran usage for human consumption. To improve the rice bran quality, sequence based allele mining at OsPLDQ1 locus (3.6 $\mathrm{Kb})$ was performed across 48 accessions representing 11 wild Oryza species, 8 accessions of African cultivated rice, and 7 Oryza sativa cultivars. From comparative sequence analysis, 216 SNPs and 30 InDels were detected at the OsPLD $\alpha 1$ locus. Phylogenetic analysis revealed 20 OsPLD 1 cDNA variants which further translated into 12 protein variants. The $O$. officinalis protein variant, when compared to Nipponbare, showed maximum variability comprising 22 amino acid substitutions and absence of two peptides and two $\beta$-sheets. Further, expression profiling indicated significant differences in transcript abundance within as well as between the OsPLD $\alpha 1$ variants. Also, a new $O s P L D \alpha 1$ transcript variant having third exon missing in it, Os01t0172400-06, has been revealed. An $O$. officinalis accession (IRGC101152) had lowest gene expression which suggests the presence of novel allele, named as OsPLD 1 1-1a (GenBank accession no. MF966931). The identified novel allele could be further deployed in the breeding programs to overcome rice bran rancidity in elite cultivars.

Rice (Oryza sativa L.) bran, a by-product after milling, is composed of pericarp, aleurone, seed coat, nucellus along with the germ and a small portion of endosperm ${ }^{1,2}$. It constitutes about $10 \%$ of the weight of rough rice, and is comprised of $12-23 \%$ oil, $14-16 \%$ protein, and $8-10 \%$ crude fibre. The rice bran oil is an oleic-linoleic-type fatty acid and is rich source of vitamin E, thiamin, niacin, and minerals like aluminium, calcium, chlorine, iron, magnesium, manganese, phosphorus, potassium, sodium, and zinc ${ }^{3}$. Further, the presence of $\omega-3$ and $\omega-6$ fatty acids, high level of unsaponifiables, and high levels of antioxidants (tocopherols, tocotrienols, and $\gamma$-Oryzanol) makes it superior to other vegetable oils as well as brightens the prospects of its utilization for humans as functional ingredient to mitigate the life-threatening disorders ${ }^{4-6}$. In addition, physico-chemical properties make it a good quality edible oil ${ }^{7}$. However, removel of husk from the paddy leads to direct contact of air with rice bran layer, which activates endogenous lipase, and results in development of off-flavor in brown rice. Further, decomposition of triacylglycerols (TAGs) in rice bran, immidiately after the process of milling, raise the levels of free fatty acids (FFAs) which makes the rice bran unsuitable for human consumption or for production of edible oil with acceptable quality ${ }^{8,9}$. In addition, rapid degradation and hydrolytic rancidity of rice bran oil limits its use for human consumption.

${ }^{1}$ School of Agricultural Biotechnology, Punjab Agricultural University, Ludhiana, Punjab, India. ${ }^{2}$ School of Biology and Ecology, University of Maine, Orono, Maine, United States of America. ${ }^{3}$ Present address: Department of Plant and Soil Science, Texas Tech University, Lubbock, Texas, United States of America. ${ }^{4}$ Present address: ICAR- National Bureau of Plant Genetic Resources, New Delhi, India. *email: kuldeep.singh4@icar.gov.in 
Rice bran is mainly comprised of TAGs, which act as the primary reserve lipids and occur in the phospholipid membrane bounded oil bodies. The aleuronic layer at maturation is comprised of living cells in which phospholipids are decomposed into fatty acids and some other chemicals by various phospholipid-degrading enzymes during storage. The phospholipid-degrading enzymes viz. phospholipases, acyl hydrolases, and lipid-oxidizing enzymes have been known as important contributors to membrane degradation ${ }^{10,11}$. The treatment of oil bodies, from rice bran fraction, with Phospholipase D (PLD) causes oil bodies disintegration followed by reduction of phosphatidylcholine levels and TAGs decomposition into FFAs ${ }^{12,13}$. Further, the FFAs interact with endosperm starches to reduces the edibility of the rice. In addition, lipoxygenases act on the FFAs which contain a 1, 4-pentadiene structure, such as linoleic and linolenic acids, and lead to their conversion into low molecular-weight volatile products which cause a stale flavor in the product ${ }^{14,15}$. Hence, it has been revealed by the the earlier studies that PLD acts as a trigger for the initiation of lipid decomposition which further leads to deterioration of the rice grain and rice bran fractions.

A total of 17 PLD genes including eight isoforms of $P L D \alpha$, two of $P L D \beta$, three of $P L D \gamma$, two of PLD , and one isoform each of $P L D \kappa$ and $P L D \varphi$ has been indicated in rice genome database ${ }^{16}$. In these isoforms, protein domain analysis has revealed several conserved domains, including the $\mathrm{HKD}(\mathrm{HxKxxxDD})$ domains (also known as PLD-C1 and PLD-C2 domains), having hydrolytic activity; the calcium/lipid-binding domain (C2 domain), resonsible for regulation of $\mathrm{Ca}^{2+}$-dependent enzyme activity through binding to $\mathrm{Ca}^{2+}$; and (3) the PX (phox consensus sequence) and $\mathrm{PH}$ (pleckstrin homology) domains, located at the $\mathrm{N}$-terminus of $\mathrm{Ca}^{2+}$ independent PLDs in place of the $\mathrm{C} 2$ domain of $\mathrm{Ca}^{2+}$ dependent PLDs ${ }^{17}$. From the rice bran fraction, a PLD protein (designated RPLD1, synonymous with OsPLD 1 ) has been purified and is found to be responsible for rice bran oil rancidity ${ }^{18}$. Suzuki et al. (2011) cloned the sequence of OsPLD $\alpha 1$ from O. sativa japonica cv. Nipponbare. This gene is $6.28-\mathrm{kb}$ in size including promoter region and is located on the chromosome 1 of rice ${ }^{19}$. The expression profiling reveals that most PLD-encoding genes are differentially expressed in many plant tissues, and during various developmental stages, suggesting their involvement in multiple developmental processes ${ }^{20}$. However, studies using transgenics have clarified that the suppressed OsPLD 1 expression results in the improvement of grain and bran stability. In addition, this gene has been reported to be unnecessary for seed maturation or germination ${ }^{21}$.

Although various stabilization methods are available to inhibit the OsPLD 1 lipolytic process ${ }^{22,23}$, such methods only lead to partial inactivation; reduce the nutritional value of rice bran; and increase the time stringency for treatment and cost of oil production ${ }^{24}$. Thus, a profitable substitute is required to reduce the rice bran rancidity. The use of breeding techniques could increase the rice bran stability against lipolytic process if genetic differences exist for this trait. However, the hassle of diminished gene pool in cultivated germplasm is specifically relevant in self pollinated crops where the degree of genetic variation in cultivars can be less than $5 \%$ of the total variation in natural populations. As a result of the selection deployed by humans during domestication in favour of desired traits, the acquired early varieties carry only a small portion of the genetic diversity available in wild species ${ }^{25}$. Hence, for the current study, we chose a representative subset of the wild rice germplasm as it constitutes a major gene pool for rice improvement ${ }^{26,27}$. Further, the allele mining technique have been successfully employed in wild species to find important variations at various loci including Badh2, OsC1, Pi ta, NBS-LRR class R-genes, Adh2, $w x$ locus, and $R c$ locus $^{28-34}$. However, thus far, wild germplasm of rice has not been assessed for the variability at OsPLD $\alpha 1$ locus.

Therefore, in the current study, a detailed analysis of DNA sequence variation at the OsPLD 1 locus (Os01g0172400) was performed in a panel of wild and cultivated rice (Oryza spp.) to identify the novel sources of alleles with lower or null activity of the enzyme. Further, validation of the identified OsPLD 1 allelic variants was conducted using quantitative reverse-transcription expression analysis.

\section{Results}

SNPs within the coding region of OsPLD $\alpha 1$. The complete coding region of OsPLD 1 , in all the wild Oryza accessions and cultivars (Table 1), was found to be $\sim 2248 \mathrm{bp}$ long and was comprised of three exons. A total of 105 SNPs and 2 insertions were identified in the coding region of OsPLD 1 gene across wild species accessions and cultivars (see Supplementary Table S1), using multiple sequence alignments. Within the first exon of OsPLD $\alpha 1$ gene (located on the gene from nucleotide position 353 to 460), only one nucleotide change (T373C) was observed across the accessions of O. officinalis, O. australiensis, O. punctata, O. minuta, and O. latifolia spp.

In addition, these species also had an insertion of nucleotide $A$ at position 459 . On the contrary, all the accessions belonging to 'AA' genome species and selected cultivars showed no polymorhism at the first exon and fall in the same cluster along with reference sequence of Nipponbare (Fig. 1a). The second exon of OsPLD $\alpha 1$, located on the gene from nucleotide position 1001 to 2897, was found to harbor the maximum variability (87 SNPs and an insertion of $\mathrm{T}_{1927}$ ) in the coding region. The detected SNPs were comprised of 65 transition changes and 22 transversions. G1141A was observed as the most frequent SNP followed by G1607A. Across all the selected wild species accessions and cultivars, maximum number of SNPs (73) were present in the species belonging to the $O$. officinalis complex (O. officinalis, O. australiensis, O. punctata, O. minuta, and O. latifolia). Moreover, O. officinalis spp. having 52 SNPs and an insertion of A at position 1927 was found most polymorphic among all (Fig. 1b). Of the total SNPs identified in O. officinalis complex, a few SNPs were also observed in the two AA genome species viz. O. meridionalis (T1135C, T1153C, T1207C, C1156T, A1747, A2099T, A2855G, and C1810T) and O. longistaminata (A1639G, A1747G, A2099T, and A2855G). AA genome species were found to carry only 27\% of the total variations detected at second exon. Cultivars including Pusa44, Feng-Ai-Zhan, Minghui63, PR114, IR64, and N22 were observed to have two nucleotide changes, G1141A and G1607A, in the second exon, however, cultivar Kitake showed no polymorhism and, thus had more relatedness to the Nipponbare when compared to rest of the cultivars.

A total of 17 polymorphic sites were reported within the third exon (located on the gene from nucleotide position 3376 to 3618 ) of the gene. Accessions of O. punctata, O. latifolia, O. minuta and O. officinalis spp. were 


\begin{tabular}{|c|c|c|c|c|}
\hline S. No. & Species & Accession \# & Genome & Country of origin \\
\hline 1 & O. glaberrima & IRGC100854 & $\mathrm{AA}$ & Congo \\
\hline 2 & O. glaberrima & IRGC101800 & AA & Senegal \\
\hline 3 & O. glaberrima & IRGC102196 & $\mathrm{AA}$ & Liberia \\
\hline 4 & O. glaberrima & IRGC102489 & $\mathrm{AA}$ & Liberia \\
\hline 5 & O. glaberrima & IRGC102512 & $\mathrm{AA}$ & Liberia \\
\hline 6 & O. glaberrima & IRGC102600b & AA & Liberia \\
\hline 7 & O. glaberrima & IRGC102925 & AA & Burkina Faso \\
\hline 8 & O. glaberrima & IRGC103750 & AA & Nigeria \\
\hline 9 & O. barthii & IRGC100117 & $\mathrm{AA}$ & Mali \\
\hline 10 & O. barthii & IRGC101317 & $\mathrm{AA}$ & Guinea \\
\hline 11 & O. barthii & IRGC104102 & $\mathrm{AA}$ & Chad \\
\hline 12 & O. barthii & IRGC 105990 & AA & Cameroon \\
\hline 13 & O. barthii & IRGC106239 & AA & Nigeria \\
\hline 14 & O. barthii & IRGC106294 & AA & Chad \\
\hline 15 & O. nivara & CR100008 & $\mathrm{AA}$ & India \\
\hline 16 & O. nivara & CR100400 & $\mathrm{AA}$ & India \\
\hline 17 & O. nivara & CR100126 & $\mathrm{AA}$ & India \\
\hline 18 & O. nivara & CR100429 & AA & India \\
\hline 19 & O. nivara & IRGC80547 & AA & India \\
\hline 20 & O. nivara & IRGC81847 & AA & India \\
\hline 21 & O. nivara & IRGC92713 & $\mathrm{AA}$ & Cambodia \\
\hline 22 & O. nivara & IRGC92930 & $\mathrm{AA}$ & Combodia \\
\hline 23 & O. nivara & IRGC100189 & $\mathrm{AA}$ & Malaysia \\
\hline 24 & O. nivara & IRGC106397 & AA & India \\
\hline 25 & O. rufipogon & CR100013 & AA & India \\
\hline 26 & O. rufipogon & IRGC80610 & $\mathrm{AA}$ & India \\
\hline 27 & O. rufipogon & IRGC81976 & $\mathrm{AA}$ & Indonesia \\
\hline 28 & O. rufipogon & IRGC83823 & $\mathrm{AA}$ & Vietnam \\
\hline 29 & O. rufipogon & IRGC89224 & $\mathrm{AA}$ & Combodia \\
\hline 30 & O. rufipogon & IRGC99551 & AA & Vietnam \\
\hline 31 & O. rufipogon & IRGC103308 & AA & Taiwan \\
\hline 32 & O. rufipogon & IRGC104308 & AA & Myanmar \\
\hline 33 & O. rufipogon & IRGC104867 & AA & Thailand \\
\hline 34 & O. rufipogon & IRGC105491 & AA & Malaysia \\
\hline 35 & O. rufipogon & IRGC105569 & $\mathrm{AA}$ & Cambodia \\
\hline 36 & O. rufipogon & IRGC105902 & $\mathrm{AA}$ & Bangladesh \\
\hline 37 & O. rufipogon & IRGC106162 & AA & Laos \\
\hline 38 & O. rufipogon & IRGC106336 & $\mathrm{AA}$ & Cambodia \\
\hline 39 & O. rufipogon & IRGC106433 & $\mathrm{AA}$ & Vietnam \\
\hline 40 & O. rufipogon & IRGC113652 & $\mathrm{AA}$ & Vietnam \\
\hline 41 & O. longistaminata & IRGC101200 & AA & Nigeria \\
\hline 42 & O. longistaminata & IRGC104301 & AA & Gambia \\
\hline 43 & O. longistaminata & IRGC105206 & AA & Ethiopia \\
\hline 44 & O. meridionalis & IRGC101146 & AA & Australia \\
\hline 45 & O. glumaepatula & IRGC100184 & AA & \begin{tabular}{|l|} 
Cuba \\
\end{tabular} \\
\hline 46 & O. glumaepatula & IRGC104387 & AA & Brazil \\
\hline 47 & O. officinalis & IRGC101152 & $\mathrm{CC}$ & Brunei \\
\hline 48 & O. officinalis & IRGC105674 & $\mathrm{CC}$ & Indonesia \\
\hline 49 & O. officinalis & IRGC106501 & $\mathrm{CC}$ & Indonesia \\
\hline 50 & O. australiensis & IRGC105275 & $\mathrm{EE}$ & Australia \\
\hline 51 & O. punctata & IRGC101434 & BBCC & Tanzania \\
\hline 52 & O. punctata & IRGC105158 & BBCC & Kenya \\
\hline 53 & O. minuta & IRGC101100 & BBCC & Philippines \\
\hline 54 & O. minuta & IRGC101128 & BBCC & Philippines \\
\hline 55 & O. latifolia & IRGC100165 & CCDD & Guatemala \\
\hline 56 & O. latifolia & IRGC105139 & CCDD & Guatemala \\
\hline
\end{tabular}

Table 1. Selected Oryza spp. accessions for allele mining at OsPLD $\alpha 1$ locus. Codes: IRGC represents the wild species accessions from the International Rice Genetic Consortium, IRRI, Philippines; CR represents accessions from National Rice Research Institute, Cuttack, India. 
observed to harbor most of the variability present on third exon, and consequently were found least related to the Nipponbare sequence (Fig. 1c). However, all the cultivars were found monomorphic for the third exon of OSPLD 1 .

SNP analysis of UTRs of OsPLD 1 gene. Untranslated regions (UTRs) play an importance role in stabilizing RNA and regulating the transcript expression. Moreover, variations within the $5^{\prime}$ UTR are also known to alter the transcription rate. Similar to the Nipponbare, UTR in all the wild species accessions and cultivars was found separated by an intronic region, however, variations in length and nucleotide sequences of two separeted UTRs (UTR1 and UTR2) were observed in different accessions due to the presence of SNPs and InDels. In comparison to the 142 nucleotide long UTR1 in Nipponbare, length of the UTR1 measured 139 nucleotides in $O$. officinalis and O. minuta spp. (see Supplementary Fig. S1) due to the presence of 5 InDels of 1 (Insertion of T), 3 (Deletion of TCT), 5 (Insertion of GCCTC), 1 (Deletion of T), and 5 nucleotides (Deletion of CCTCC) at positions 4, 58, 80, 102, and 124, respectively. Additionaly, SNPs A40G, C50A, C101G, C102T, and C141T were also observed in the UTR1 region of these species. Across all the sequenced rice cultivars and AA genomic wild species, an InDel of 3 nucleotides (Inserion of CTC) at position 99 was observed in the UTR1. Moreover, cultivars Feng-Ai-Zhan, Pusa44, IR64, and Minghui 63 also had a deletion of $\mathrm{C}$ at nucleotide position 69. In UTR2, a deletion of 10 nucleotides (AATCCAAATC) at nucleotide position 16, was detected in O. officinalis, O. minuta, O. punctata, and O. australiensis spp., when compared to the Nipponbare (see Supplementary Fig. S2). In addition, 3 SNPs, G5A, A21T, A22C and T23A were observed in these species as well. However, all the accessions of AA genomic species and all the cultivars were found monomorphic for UTR2 nucleotide sequence.

SNPs within intronic regions. Across the wild species and cultivars, we detected 101 SNPs and 22 InDels in the intronic region of $O s P L D \alpha 1$ gene, in comparison to the Nipponbare (see Supplementary Table S2). Within the first intron (located on the gene from nucleotide position 143 to 315 ), 50 nucleotide changes were identified and most of them (45) were detected in the accessions of $O$. officinalis (IR101152, IR105674, IR106501), $O$. minuta (IR101100, IR101128), O. punctata (IR105158), O. australiensis (IR105275), and O. latifolia (IR105139) spp. The remaining 5 SNPs (C187T, C257G, A286T, T289C, and G309T) were detected in the O. meridionalis accession (IR101146). In addition to the nucleotide changes, 4 InDels of 9 (+TCGCTGTAC $222-230$ ), 11 $\left(+\right.$ ATTTCTTATCC $\left._{147-157}\right), 13$ (+ ATCCTCGCTTACC $\left._{147-159}\right)$, and 6 ( - AGGTAG $_{176-181}$ ) nucleotides, were also observed in the species belonging to the O. officinalis complex. Across the cultivars, only a single InDel of 1 nucleotide long $\left(+\mathrm{G}_{315}\right)$ was detected in Pusa44, Minghui63, and Feng-Ai-Zhan. No SNP or InDel was detected across the accessions of O. glaberrima, O. barthii, O. nivara, O. glumaepatula, and O. longistaminata. Phylogenetic tree generated from the nucleotide sequence of first intron showed that the accessions of selected species and cultivars fall into two clades (Fig. 2a).

Second intron (located on the gene from nucleotide position 461 to 1000) sequence was only available for AA genome species and cultivars, and could not be obtained for the rest of species even after repeated efforts. In total, 11 SNPs and an Indel of 4 nucleotides were detected on this intron. A467G SNP was found as the most frequent as it was detected across all the AA genome species and rice cultivars. O. longistaminata accessions (IR104301 and IR101200) harbour maximum variability on the second exon, and thus were found most distant to the Nipponbare (Fig. 2b). The third intron (cover 2898 to 3375 nucleotide position on the gene) carried 40 nucleotide changes and 6 InDels. Among AA genome species, O. meridionalis had maximum number of SNPs; however O. officinalis was observed to have maximum variability (SNPs and InDels) across all the wild species. Within the third intron, two large InDels of $18 \mathrm{bp}$ (+ATGCATCAGAGATCATTT) and 30bp (CTAATGATCAAGCTAGTAACTTCATCTCCT) were detected from the nucleotide positions 2988 to 3006 and from 3295 to 3324, respectively. Accessions of O. officinalis, O. minuta, and O. punctata were falling in the same cluster, and were found least related to the Nipponbare (Fig. 2c).

OsPLD $\alpha 1$ cDNA and protein variants. A panel of 63 OsPLD 1 cDNA sequence assemblies from wild Oryza species accessions and cultivars, each containing $\sim 2248$ bp were analyzed. Phylogenetic analysis revealed the presence of OsPLD $\alpha 1$ variants in 48 accessions from 11 wild Oryza spp., 8 accessions of O. glaberrima, and 7 Oryza sativa cultivars (Fig. 3). These OsPLD $\alpha 1$ variants were further classified into two major clusters that distinguish AA genomic spp. (O. glaberrima, O. barthii, O. nivara, O. rufipogon, O. longistaminata, O. meridionalis, and O. glumaepatula) from other genomic spp. (O. officinalis, O. australiensis, O. punctata, and O. minuta). Accessions of $O$. latifolia were falling in between the two clusters. The reference sequence of Nipponbare showed more closeness to japonica cultivar Kitake than to indica cvs. Minghui 63, IR 64, PR 114, Pusa 44, Feng-Ai-Zhan, and N22. The analysis revealed that polymorhic sites were frequently observed in the wild spp. having genome other than AA genome. A total of 20 OsPLD $\alpha 1$ variants were identified based on the nucleotide variations in the cDNA sequences of selected wild species accessions and cultivars.

To determine if the detected nucleotide variations in the coding region of the gene further lead to any alterations in the gene, the cDNA structures of the representative Oryza accessions were aligned with the Nipponbare (see Supplementary Fig. S3). The results revealed that all AA genomic spp. were having the similar number of exons as of the Nipponbare. Exon 1 and Exon 3 were found to be of same length in all the studied species whereas Exon2 showed alterations in the species belonging to O. officinalis complex. At the end of first exon, a gap of 193bp (from nucleotide position 109 to 301) was detected in O. australiensis, O. punctata, and O. latifolia accessions while a smaller gap of $77 \mathrm{bp}$ (from nucleotide position 109 to 184) was detected in the O. minuta and $O$. officinalis accessions. Interestingly, O. officinalis accession had an additional gap within the exon 2 from the nucleotide position 1081 to 1137. 


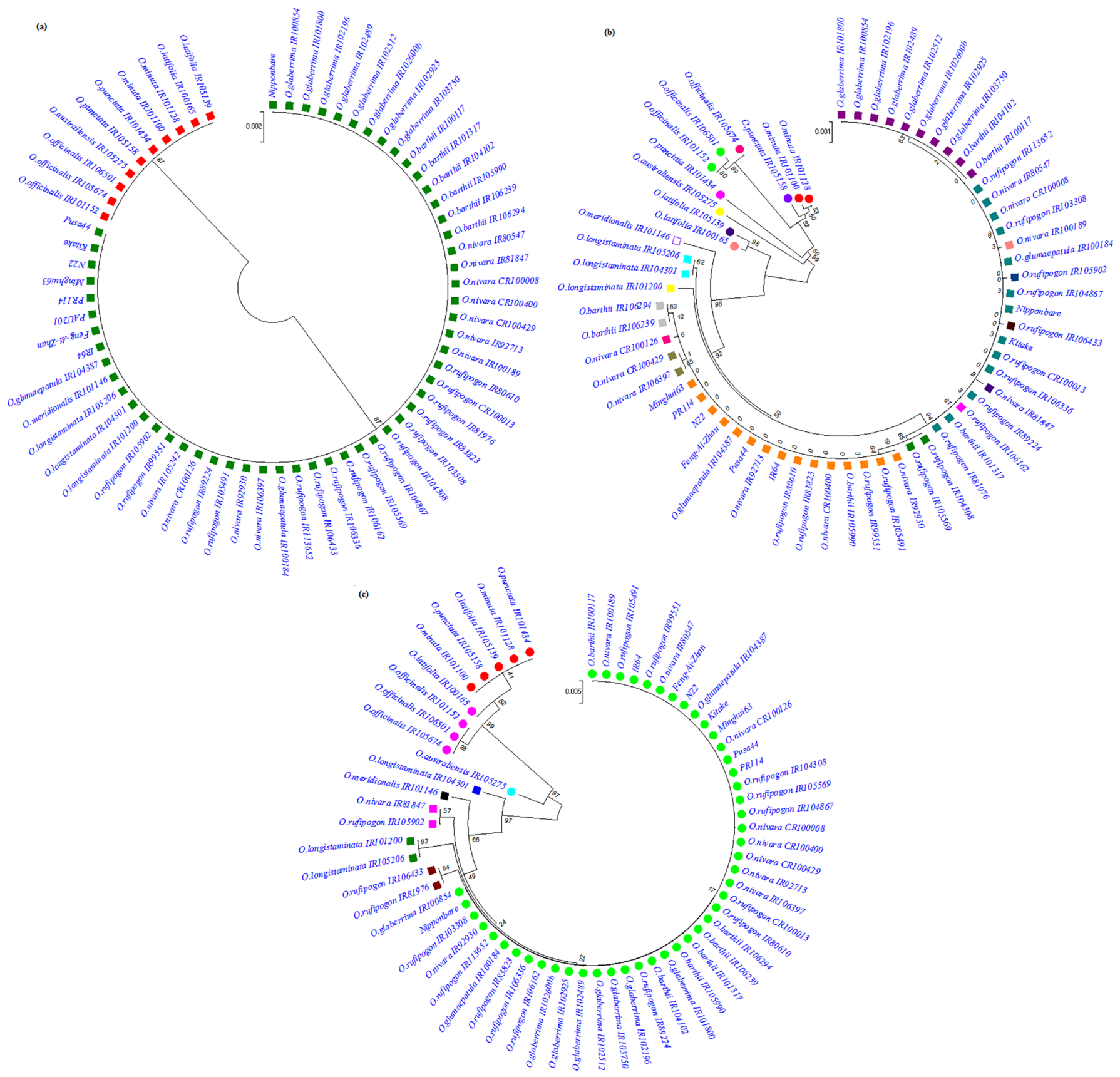

Figure 1. Evolutionary relationship across different wild species accessions and cultivars based on the nucleotide sequence of $O s P L D \alpha 1$ exons (a) first exon, (b) second exon, (c) third exon using a neighbor -joining algorithm calculated by boot-strap value of 1000 replicate.

Further, from comparative sequence analysis, 107 nucleotide changes (105 SNPs and 2 insertions) were observed across the exons (see Supplementary Table S1). The identified SNPs included 81 transitions and 24 transversions, while G/A transition was the most common (23.80\%). Of the identified nucleotide changes, 16 SNPs and 2 insertions were found to be non-synonymous SNPs/indels that really have the potential to become a novel functional alleles (Table 2). The identified 20 OsPLD $\alpha 1$ cDNA variants translated into 12 OsPLD $\alpha 1$ proteins variants (designated as I to XII) and the amino acids substitutions in these variants, in comparison to the reference protein sequence of Nipponbare, have been shown in the Table 3. The proteins predicted from O. officinalis complex clade had more polymorphic amino acids in comparison to the clade containing AA genome species. In addition to the amino acid substitutions across different regions of the the protein variants, 15 amino acids long peptide (KFVEGIEDTVGKGAT) was found missing at $36^{\text {th }}$ position of the variants VI-XII (see Supplementary Fig. S4). Another 18 amino acids long peptide (RIVSFVGGLDLCDGRYDT) at position 336 was found missing only in the variant X (see Supplementary Fig. S5). As a result, X protein variant which comprised of three 

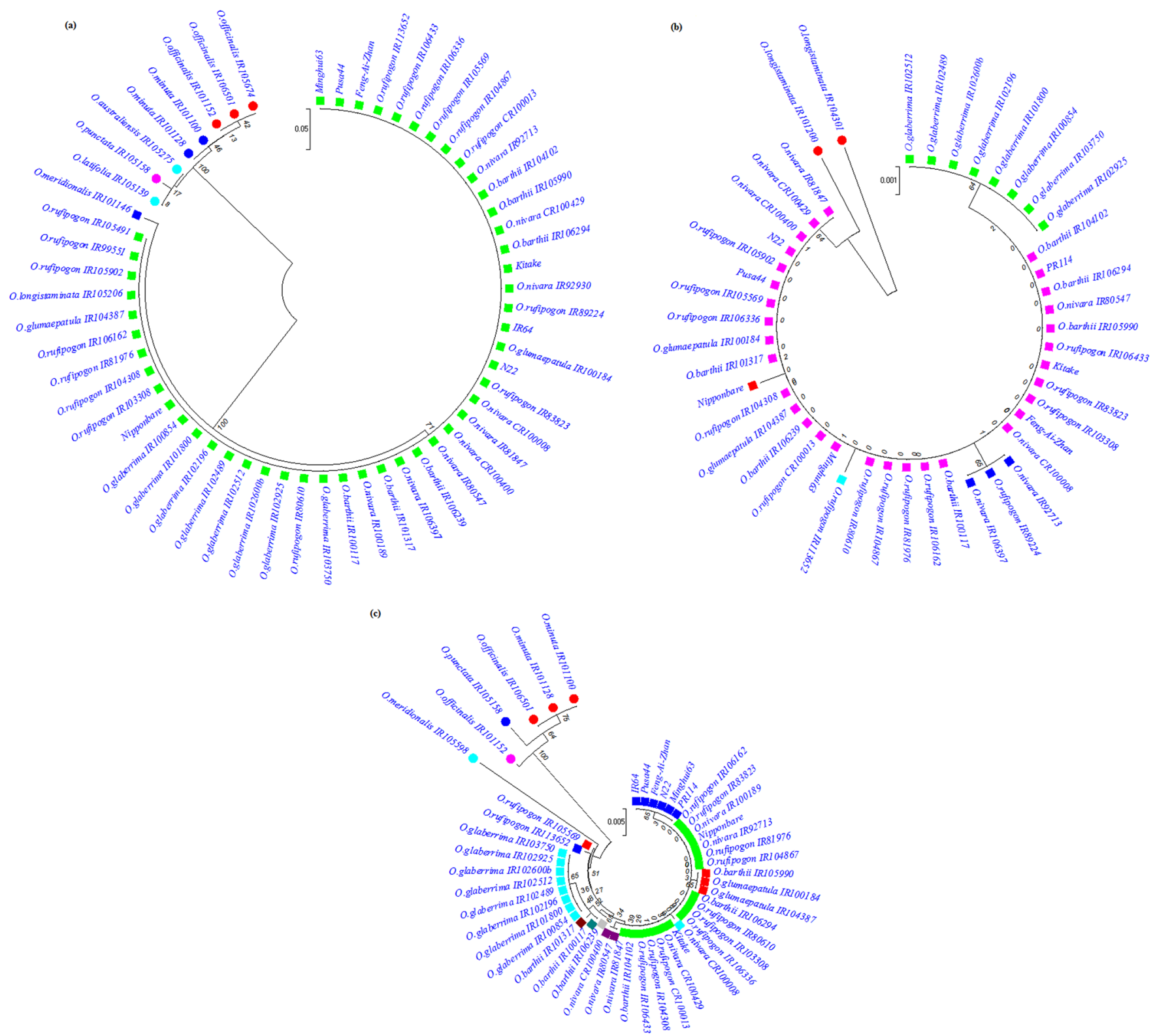

Figure 2. Evolutionary relationship across different wild species accessions and cultivars based on the nucleotide sequence of $O s P L D \alpha 1$ introns (a) first intron, (b) second intron, (c) third intron, using a neighbor -joining algorithm calculated by boot-strap value of 1000 replicate.

accessions of O. officinalis (IR101152, IR106501, and IR105674) was having maximum number, twenty two, of amino acid substitutions, and had both the peptides missing.

Domains and motifs in OsPLD $\alpha 1$ variants. Domains/motifs were determined and compared in OsPLD $\alpha 1$ protein and its 12 variants. Three important domains including one copy of C2 domain and two copies of Phospholipase D Active site (PLDc) motif were detected in the reference OsPLD $\alpha 1$ protein. C2 domain was found to be present in all the OsPLD 1 variants, however, length of this domain was found 17 amino acids shorter than in VI-XII protein variants. The alignment of C2 domain from reference protein to the variants showed the absence of KFVEGIEDTVGVGKGAT peptide at 36 amino acid position (see Supplementary Fig. S4). In addition to the missing peptide, two amino acid substitutions have also been reported in the $\mathrm{C} 2$ domain which included Isoleucine to valine substitution (at position 76) in variant X, XI and XII and asparagine to aspartate substitution (at position 77) in variant X. Further analysis revealed the presence of two copies of PLDc motif in the PLDalphal protein (PLDc-I covering 330 to 368 amino acid position and PLDc-II covering 658 to 685 position of amino acids in the PLDalphal protein) in all the variants except variant X in which PLDc-I motif was found missing. Alignment of 330 to 368 amino acid sequences from PLD 1 protein to other variants revealed the absence of RIVSFVGGLDLCDGR peptide at amino acid position 354 and eight amino acid substitutions in variant X (see Supplementary Fig. S5). 


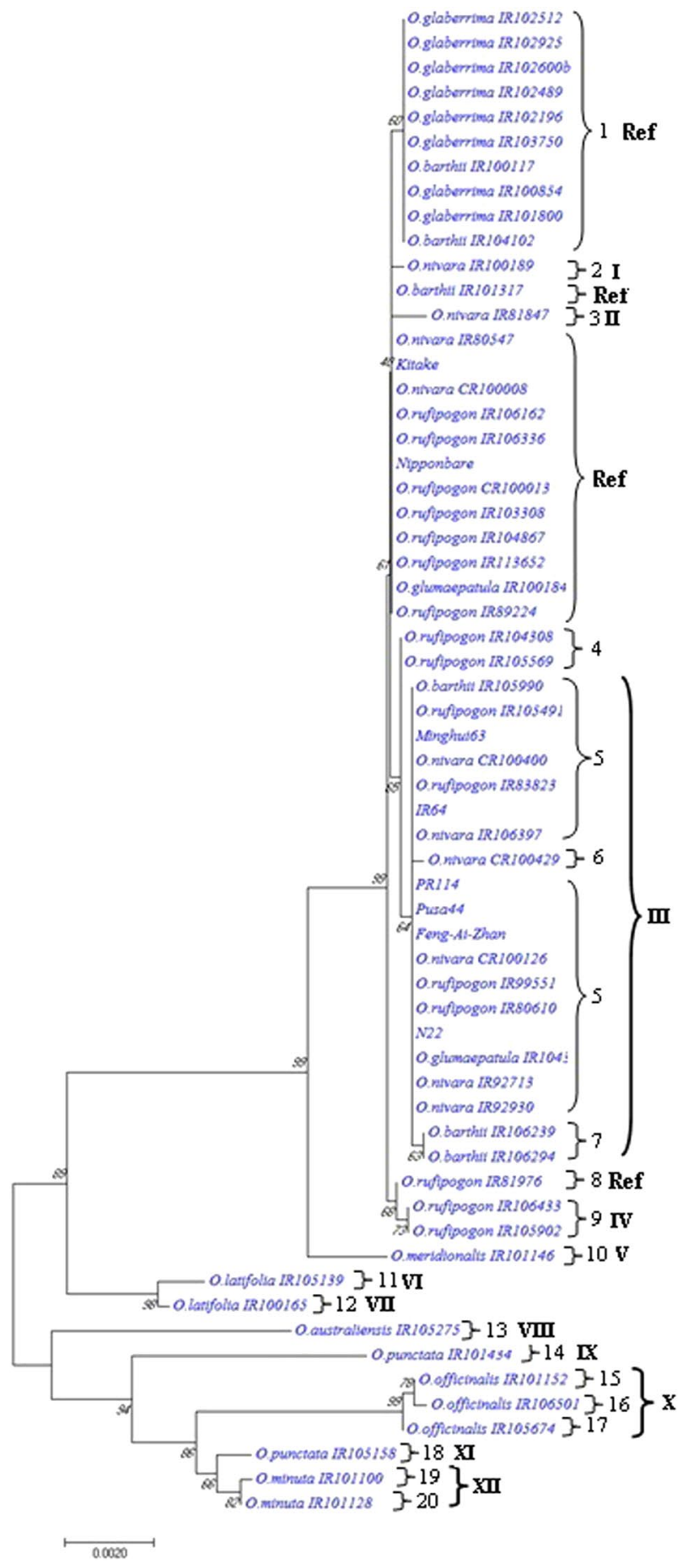

Figure 3. Phylogenetic relationship of $O S P L D \alpha 1$ across Nipponbare, wild species accessions, and cultivars of rice based on the nucleotide sequence data of cDNA. Phylogenetic tree was generated using a neighbor - joining algorithm calculated by boot-strap value of 1000 replicate. The number 1-20 indicates 20 OsPLD 1 variants based on the nucleotide sequences of cDNA while the numbers I to XII indicate protein variants. 'Ref' denotes the nucleotide sequences variants which translates into the amino acid sequence same as that of the reference OsPLD $\alpha 1$ protein sequence of Nipponbare.

Tertiary structure prediction of OsPLD 1 protein in Nipponbare and variant X. Homology modeling approach was employed to determine the three-dimensional structures of OsPLD $\alpha 1$ protein from Nipponbare and a representative accession (IR101152 accession O. officinalis) of variant X. The MPI Bioinformatics Toolkit (http://toolkit.tuebingen.mpg.de) selected 1v0w as the template for OsPLD $\alpha 1$ protein structure prediction. 1v0w represents the first crystal structure of Phospholipase-D from bacterial source Streptomyces sp. strain $\mathrm{PMF}^{35}$. By using this template, structures were predicted for OsPLD 1 protein in 


\begin{tabular}{|c|c|c|c|c|c|c|c|}
\hline S.No. & Position $^{\#}$ & Alleles* & Codon change & S.No. & Position $^{\#}$ & Alleles* & Codon change \\
\hline 1 & 373 & $\mathrm{~T} / \mathrm{C}^{\dagger}$ & - & 54 & 1964 & $\mathrm{~T} / \mathrm{C}^{\dagger}$ & - \\
\hline 2 & 1027 & $\mathrm{G}^{-\mathrm{A}^{\dagger}}$ & - & 55 & 1967 & $\mathrm{C} / \mathrm{T}^{\dagger}$ & - \\
\hline 3 & 1043 & ${\mathrm{G} / \mathrm{A}^{\dagger}}^{\dagger}$ & - & 56 & 1997 & ${\mathrm{G} / \mathrm{A}^{\dagger}}^{+}$ & - \\
\hline 4 & 1060 & $\mathrm{~T} / \mathrm{C}^{\dagger}$ & - & 57 & 2048 & $\mathrm{~T} / \mathrm{C}^{\dagger}$ & - \\
\hline 5 & 1084 & ${\mathrm{~T} / \mathrm{C}^{\dagger}}^{\dagger}$ & - & 58 & 2077 & $\mathrm{C} / \mathrm{A}^{\dagger+}$ & Thr395Asn \\
\hline 6 & 1087 & $\mathrm{~A} / \mathrm{T}^{\dagger \dagger}$ & - & 59 & 2081 & $\mathrm{~A} / \mathrm{G}^{\dagger}$ & - \\
\hline 7 & 1087 & $\mathrm{~A} / \mathrm{C}^{\dagger \dagger}$ & - & 60 & 2084 & $\mathrm{~A} / \mathrm{G}^{\dagger}$ & - \\
\hline 8 & 1090 & $\mathrm{G} / \mathrm{C}^{\dagger \dagger}$ & - & 61 & 2087 & $\mathrm{C} / \mathrm{A}^{\dagger \dagger}$ & - \\
\hline 9 & 1118 & $\mathrm{~A} / \mathrm{G}^{\dagger}$ & Ile76Val & 62 & 2087 & $\mathrm{C} / \mathrm{T}^{\dagger}$ & - \\
\hline 10 & 1120 & $\mathrm{C} / \mathrm{T}^{\dagger}$ & - & 63 & 2089 & $\mathrm{~A} / \mathrm{C}^{\dagger \dagger}$ & Lys399Thr \\
\hline 11 & 1121 & $\mathrm{~A} / \mathrm{G}^{\dagger}$ & Asn77Asp & 64 & 2099 & $\mathrm{~A} / \mathrm{T}^{\dagger \dagger}$ & - \\
\hline 12 & 1123 & $\mathrm{C} / \mathrm{T}^{\dagger}$ & - & 65 & 2102 & $\mathrm{~T} / \mathrm{A}^{\dagger \dagger}$ & - \\
\hline 13 & 1135 & $\mathrm{~T} / \mathrm{C}^{\dagger}$ & - & 66 & 2108 & $\mathrm{G} / \mathrm{A}^{\dagger}$ & - \\
\hline 14 & 1141 & ${\mathrm{G} / \mathrm{A}^{\dagger}}^{+}$ & - & 67 & 2174 & $\mathrm{G}^{\mathrm{A}} \mathrm{A}^{\dagger}$ & - \\
\hline 15 & 1153 & $\mathrm{~T} / \mathrm{C}^{\dagger}$ & - & 68 & 2210 & $\mathrm{~T} / \mathrm{A}^{\dagger \dagger}$ & - \\
\hline 16 & 1156 & $\mathrm{C} / \mathrm{T}^{\dagger}$ & - & 69 & 2232 & ${\mathrm{G} / \mathrm{A}^{\dagger}}^{\dagger}$ & - \\
\hline 17 & 1162 & $\mathrm{~T} / \mathrm{C}^{\dagger}$ & - & 70 & 2258 & $\mathrm{~T} / \mathrm{C}^{\dagger}$ & - \\
\hline 18 & 1168 & $\mathrm{~T} / \mathrm{A}^{\dagger \dagger}$ & - & 71 & 2297 & $\mathrm{~A} / \mathrm{C}^{\dagger \dagger}$ & - \\
\hline 19 & 1207 & $\mathrm{~T} / \mathrm{C}^{\dagger}$ & - & 72 & 2335 & $\mathrm{C} / \mathrm{T}^{\dagger}$ & Pro481Leu \\
\hline 20 & 1210 & ${\mathrm{G} / \mathrm{A}^{\dagger}}^{\dagger}$ & - & 73 & 2363 & $\mathrm{~T} / \mathrm{C}^{\dagger}$ & - \\
\hline 21 & 1243 & $\mathrm{C} / \mathrm{T}^{\dagger}$ & - & 74 & 2414 & $\mathrm{~A} / \mathrm{T}^{\dagger \dagger}$ & - \\
\hline 22 & 1258 & $\mathrm{~T} / \mathrm{C}^{\dagger}$ & - & 75 & 2456 & $\mathrm{~A} / \mathrm{T}^{\dagger \dagger}$ & - \\
\hline 23 & 1273 & $\mathrm{C} / \mathrm{T}^{\dagger}$ & - & 76 & 2498 & $\mathrm{C} / \mathrm{T}^{\dagger}$ & - \\
\hline 24 & 1275 & $\mathrm{G} / \mathrm{C}^{\dagger \dagger}$ & Arg128Thr & 77 & 2558 & $\mathrm{G} / \mathrm{T}^{\dagger \dagger}$ & - \\
\hline 25 & 1282 & $\mathrm{C} / \mathrm{T}^{\dagger}$ & - & 78 & 2582 & $\mathrm{C} / \mathrm{T}^{\dagger}$ & - \\
\hline 26 & 1303 & $\mathrm{C} / \mathrm{T}^{\dagger}$ & - & 79 & 2627 & $\mathrm{G} / \mathrm{A}^{\dagger}$ & - \\
\hline 27 & 1308 & $\mathrm{C} / \mathrm{T}^{\dagger}$ & \begin{tabular}{|l|} 
Pro139Leu \\
\end{tabular} & 80 & 2636 & $\mathrm{~A} / \mathrm{C}^{\dagger \dagger}$ & - \\
\hline 28 & 1348 & $\mathrm{C} / \mathrm{T}^{\dagger}$ & - & 81 & 2657 & $\mathrm{~A} / \mathrm{T}^{\dagger \dagger}$ & - \\
\hline 29 & 1369 & $\mathrm{~T} / \mathrm{A}^{\dagger+}$ & Asn159Lys & 82 & 2675 & $\mathrm{G} / \mathrm{A}^{\dagger}$ & - \\
\hline 30 & 1386 & $\mathrm{G} / \mathrm{A}^{+}$ & - & 83 & 2715 & $\mathrm{C} / \mathrm{T}^{\dagger}$ & - \\
\hline 31 & 1387 & $\mathrm{C} / \mathrm{T}^{\dagger}$ & Arg165His & 84 & 2727 & $\mathrm{G} / \mathrm{A}^{\dagger}$ & - \\
\hline 32 & 1450 & $\mathrm{C} / \mathrm{G}^{\dagger+}$ & - & 85 & 2738 & ${\mathrm{G} / \mathrm{A}^{\dagger}}^{+}$ & - \\
\hline 33 & 1516 & $\mathrm{C} / \mathrm{T}^{\dagger}$ & - & 86 & 2794 & $\mathrm{C} / \mathrm{G}^{\dagger \dagger}$ & Ala634Gly \\
\hline 34 & 1570 & $\mathrm{~A} / \mathrm{G}^{\dagger}$ & - & 87 & 2795 & $\mathrm{~T} / \mathrm{C}^{\dagger}$ & - \\
\hline 35 & 1607 & ${\mathrm{G} / \mathrm{A}^{\dagger}}^{+}$ & Glu239Lys & 88 & 2855 & $\mathrm{~A} / \mathrm{G}^{\dagger}$ & - \\
\hline 36 & 1619 & ${\mathrm{G} / \mathrm{A}^{\dagger}}^{+}$ & Val729Ile & 89 & 3407 & $\mathrm{~A} / \mathrm{G}^{\dagger}$ & - \\
\hline 37 & 1639 & $\mathrm{~A} / \mathrm{G}^{\dagger}$ & - & 90 & 3425 & $\mathrm{G} / \mathrm{A}^{\dagger}$ & - \\
\hline 38 & 1723 & $\mathrm{~T} / \mathrm{C}^{\dagger}$ & - & 91 & 3446 & $\mathrm{~T} / \mathrm{C}^{\dagger}$ & - \\
\hline 39 & 1747 & $\mathrm{~A} / \mathrm{G}^{\dagger}$ & - & 92 & 3452 & $\mathrm{C} / \mathrm{T}^{\dagger}$ & - \\
\hline 40 & 1753 & ${\mathrm{G} / \mathrm{A}^{\dagger}}^{\dagger}$ & - & 93 & 3461 & $\mathrm{C} / \mathrm{T}^{\dagger}$ & - \\
\hline 41 & 1760 & $\mathrm{~T} / \mathrm{C}^{\dagger}$ & - & 94 & 3481 & $\mathrm{C} / \mathrm{T}^{\dagger}$ & - \\
\hline 42 & 1762 & ${\mathrm{G} / \mathrm{A}^{\dagger}}^{+}$ & - & 95 & 3485 & $\mathrm{G} / \mathrm{A}^{\dagger}$ & - \\
\hline 43 & 1788 & $\mathrm{~A} / \mathrm{C}^{\dagger \dagger}$ & Glu299Ala & 96 & 3488 & $\mathrm{C} / \mathrm{T}^{\dagger}$ & - \\
\hline 44 & 1789 & $\mathrm{~A} / \mathrm{T}^{\dagger \dagger}$ & - & 97 & 3494 & $\mathrm{~A} / \mathrm{G}^{\dagger}$ & - \\
\hline 45 & 1808 & ${\mathrm{G} / \mathrm{A}^{\dagger}}^{+}$ & Asp306Asn & 98 & 3497 & $\mathrm{~A} / \mathrm{G}^{\dagger}$ & - \\
\hline 46 & 1810 & $\mathrm{C} / \mathrm{T}^{\dagger}$ & - & 99 & 3503 & $\mathrm{~T} / \mathrm{G}^{\dagger \dagger}$ & - \\
\hline 47 & 1825 & $\mathrm{~A} / \mathrm{G}^{\dagger}$ & - & 100 & 3549 & $\mathrm{G} / \mathrm{A}^{\dagger}$ & - \\
\hline 48 & 1850 & ${\mathrm{G} / \mathrm{A}^{\dagger}}^{\dagger}$ & Gly320Ser & 101 & 3551 & $\mathrm{~A} / \mathrm{C}^{\dagger \dagger}$ & - \\
\hline 49 & 1858 & $\mathrm{~T} / \mathrm{C}^{\dagger}$ & - & 102 & 3553 & $\mathrm{~T} / \mathrm{C}^{\dagger}$ & Met728Thr \\
\hline 50 & 1870 & ${\mathrm{G} / \mathrm{A}^{\dagger}}^{+}$ & - & 103 & 3554 & $\mathrm{G} / \mathrm{A}^{\dagger}$ & - \\
\hline 51 & 1873 & ${\mathrm{G} / \mathrm{A}^{\dagger}}^{+}$ & - & 104 & 3560 & $\mathrm{~T} / \mathrm{C}^{\dagger}$ & - \\
\hline 52 & 1879 & $\mathrm{~A} / \mathrm{G}^{\dagger}$ & - & 105 & 3563 & $\mathrm{~T} / \mathrm{C}^{\dagger}$ & - \\
\hline 53 & 1962 & $\mathrm{~A} / \mathrm{G}^{\dagger}$ & - & & & & \\
\hline
\end{tabular}

Table 2. Translational modification sites observed at OsPLD $\alpha 1$ locus across the wild Oryza species accessions and Oryza cultivars as compared to the Nipponbare reference sequence. *In addition to the identified SNPs, 2 insertions including $\mathrm{A}$ at nucleotide position 459 and $\mathrm{T}$ at nucleotide position 1927 were also detected. Insertion of $\mathrm{A}_{459}$ led to deletion of KFVEGIEDTVGVGKGAT peptide at amino acid position 36. Insertion of $\mathrm{T}_{1927}$ led to amino acid substitutions viz. Leu345Phe, Pro346Ala, Agn347Lys, Gln348Pro, Ser350Leu, Gln351Pro, Gln352Thr, Arg353Lys, Gln372Glu, Tyr373Asp, His374Ser, Ser375Gln, Phe377Arg, and Arg378Trp and a deletion of RIVSFVGGLDLCDGR peptide at amino acid position 354. \#The SNP position was calculated relative to the reference sequence of OsPLD $\alpha 1$ in Nipponbare (RAP locus ID Os01g0172400). Transitions ${ }^{\dagger}$ and transversions ${ }^{\dagger \dagger}$ observed as nucleotide substitutions. 


\begin{tabular}{|c|c|c|c|c|c|c|c|c|c|c|c|c|c|}
\hline Protein $^{a}$ & Ref.c $^{c}$ & I & II & III & IV & V & VI & VII & VIII & IX & $\mathrm{X}$ & XI & XII \\
\hline Variant $^{\mathrm{b}}$ & $1,4,8$ & 2 & 3 & $\begin{array}{l}5, \\
6,7\end{array}$ & 9 & 10 & 11 & 12 & 13 & 14 & $\begin{array}{l}15, \\
16, \\
17\end{array}$ & 18 & 19,20 \\
\hline 76 & I & I & I & I & I & I & I & I & I & I & $\mathrm{V}$ & $\mathrm{V}$ & $\mathrm{V}$ \\
\hline 77 & $\mathrm{~N}$ & $\mathrm{~N}$ & $\mathrm{~N}$ & $\mathrm{~N}$ & $\mathrm{~N}$ & $\mathrm{~N}$ & $\mathrm{~N}$ & $\mathrm{~N}$ & $\mathrm{~N}$ & $\mathrm{~N}$ & $\mathrm{D}$ & $\mathrm{N}$ & $\mathrm{N}$ \\
\hline 128 & $\mathrm{R}$ & $\mathrm{R}$ & $R$ & $\mathrm{R}$ & $\mathrm{R}$ & $\mathrm{R}$ & $\mathrm{R}$ & $\mathrm{R}$ & $\mathrm{T}$ & $\mathrm{T}$ & $\mathrm{T}$ & $\mathrm{T}$ & $\mathrm{T}$ \\
\hline 139 & $\mathrm{P}$ & $\mathrm{P}$ & $\mathrm{P}$ & $\mathrm{P}$ & $\mathrm{P}$ & $\mathrm{P}$ & $\mathrm{P}$ & $\mathrm{P}$ & $\mathrm{P}$ & $\mathrm{P}$ & $\mathrm{P}$ & $\mathrm{L}$ & $\mathrm{P}$ \\
\hline 159 & $\mathrm{~N}$ & $\mathrm{~N}$ & $\mathrm{~N}$ & $\mathrm{~N}$ & $\mathrm{~N}$ & $\mathrm{~N}$ & $\mathrm{~N}$ & $\mathrm{~N}$ & $\mathrm{~K}$ & $\mathrm{~N}$ & $\mathrm{~N}$ & $\mathrm{~N}$ & $\mathrm{~N}$ \\
\hline 165 & $\mathrm{R}$ & $\mathrm{R}$ & $\mathrm{H}$ & $\mathrm{R}$ & $R$ & $R$ & $\mathrm{R}$ & $\mathrm{R}$ & $\mathrm{R}$ & $\mathrm{R}$ & $\mathrm{R}$ & $\mathrm{R}$ & $\mathrm{R}$ \\
\hline 239 & $\mathrm{E}$ & $\mathrm{E}$ & E & $\mathrm{K}$ & E & E & $\mathrm{E}$ & $\mathrm{E}$ & $\mathrm{E}$ & $\mathrm{E}$ & $\mathrm{E}$ & E & $\mathrm{E}$ \\
\hline 243 & V & $\mathrm{V}$ & $\mathrm{V}$ & V & $\mathrm{V}$ & $\mathrm{V}$ & V & $\mathrm{V}$ & I & $\mathrm{V}$ & V & $\mathrm{V}$ & $\mathrm{V}$ \\
\hline 299 & E & $\mathrm{E}$ & $\mathrm{E}$ & E & $\mathrm{E}$ & $\mathrm{E}$ & $\mathrm{E}$ & $\mathrm{E}$ & $\mathrm{A}$ & A & A & A & A \\
\hline 306 & $\mathrm{D}$ & $\mathrm{D}$ & $\mathrm{D}$ & $\mathrm{D}$ & $\mathrm{N}$ & $\mathrm{D}$ & $\mathrm{D}$ & $\mathrm{D}$ & $\mathrm{D}$ & $\mathrm{D}$ & $\mathrm{D}$ & $\mathrm{D}$ & $\mathrm{D}$ \\
\hline 320 & G & G & G & G & G & G & G & G & S & G & G & G & G \\
\hline 345 & $\mathrm{~L}$ & $L$ & $\mathrm{~L}$ & $\mathrm{~L}$ & $\mathrm{~L}$ & $\mathrm{~L}$ & $\mathrm{~L}$ & $\mathrm{~L}$ & L & $\mathrm{L}$ & $F$ & $\mathrm{~L}$ & $\mathrm{~L}$ \\
\hline 346 & $\mathrm{P}$ & $\mathrm{P}$ & $\mathrm{P}$ & $\mathrm{P}$ & $\mathrm{P}$ & $\mathrm{P}$ & $\mathrm{P}$ & $\mathrm{P}$ & $\mathrm{P}$ & $\mathrm{P}$ & A & $\mathrm{P}$ & $\mathrm{P}$ \\
\hline 347 & $\mathrm{~N}$ & $\mathrm{~N}$ & $\mathrm{~N}$ & $\mathrm{~N}$ & $\mathrm{~N}$ & $\mathrm{~N}$ & $\mathrm{~N}$ & $\mathrm{~N}$ & $\mathrm{~N}$ & $\mathrm{~N}$ & K & $\mathrm{N}$ & $\mathrm{N}$ \\
\hline 348 & Q & Q & Q & Q & Q & Q & Q & Q & Q & Q & $\mathrm{P}$ & Q & Q \\
\hline 350 & S & S & S & S & S & S & S & S & S & S & $\mathrm{L}$ & S & S \\
\hline 351 & Q & Q & Q & Q & Q & Q & Q & Q & Q & Q & P & Q & Q \\
\hline 352 & Q & Q & Q & Q & Q & Q & Q & Q & Q & Q & $\mathrm{T}$ & Q & Q \\
\hline 353 & $\mathrm{R}$ & $\mathrm{R}$ & $\mathrm{R}$ & $\mathrm{R}$ & $\mathrm{R}$ & $\mathrm{R}$ & $\mathrm{R}$ & R & $\mathrm{R}$ & R & $\mathrm{K}$ & $\mathrm{R}$ & $\mathrm{R}$ \\
\hline 372 & Q & Q & Q & Q & Q & Q & Q & Q & Q & Q & E & Q & Q \\
\hline 373 & $\mathrm{Y}$ & $\mathrm{Y}$ & $\mathrm{Y}$ & $\mathrm{Y}$ & $\mathrm{Y}$ & $\mathrm{Y}$ & Y & Y & $\mathrm{Y}$ & Y & D & $\mathrm{Y}$ & Y \\
\hline 374 & $\mathrm{H}$ & $\mathrm{H}$ & $\mathrm{H}$ & $\mathrm{H}$ & $\mathrm{H}$ & $\mathrm{H}$ & $\mathrm{H}$ & $\mathrm{H}$ & $\mathrm{H}$ & $\mathrm{H}$ & S & $\mathrm{H}$ & $\mathrm{H}$ \\
\hline 375 & S & S & S & S & S & S & S & S & S & S & Q & S & S \\
\hline 377 & F & F & F & F & F & F & F & F & F & F & $\mathrm{R}$ & F & F \\
\hline 378 & $\mathrm{R}$ & $\mathrm{R}$ & $\mathrm{R}$ & $\mathrm{R}$ & $\mathrm{R}$ & $\mathrm{R}$ & $\mathrm{R}$ & $\mathrm{R}$ & $\mathrm{R}$ & $\mathrm{R}$ & W & $\mathrm{R}$ & $\mathrm{R}$ \\
\hline 395 & $\mathrm{~T}$ & $\mathrm{~T}$ & $\mathrm{~T}$ & $\mathrm{~T}$ & $\mathrm{~T}$ & $\mathrm{~N}$ & $\mathrm{~N}$ & $\mathrm{~N}$ & $\mathrm{~N}$ & $\mathrm{~N}$ & $\mathrm{~N}$ & $\mathrm{~N}$ & $\mathrm{~N}$ \\
\hline 399 & $\mathrm{~K}$ & $\mathrm{~N}$ & K & $\mathrm{K}$ & K & K & $\mathrm{K}$ & K & $\mathrm{T}$ & $\mathrm{K}$ & $\mathrm{T}$ & $\mathrm{T}$ & $\mathrm{T}$ \\
\hline 481 & $\mathrm{P}$ & $\mathrm{P}$ & $\mathrm{P}$ & $\mathrm{P}$ & $\mathrm{P}$ & $\mathrm{P}$ & $\mathrm{P}$ & $\mathrm{P}$ & L & $\mathrm{P}$ & $\mathrm{P}$ & $\mathrm{P}$ & $\mathrm{P}$ \\
\hline 634 & A & A & A & A & A & A & G & A & G & G & G & A & A \\
\hline 728 & M & $\mathrm{M}$ & M & M & $\mathrm{M}$ & M & M & $\mathrm{T}$ & M & $\mathrm{T}$ & $\mathrm{T}$ & $\mathrm{T}$ & $\mathrm{T}$ \\
\hline
\end{tabular}

Table 3. Amino acid variations among 20 OsPLD $\alpha 1$ variants. Amino acids (indicated with the letter code) and their positions (indicated in numbers) in the OsPLD $\alpha 1$ variants. Amino acids with highlighted background show substitutions in OsPLD 11 protein variants in comparison to the OsPLD $\alpha 1$ protein (AB571657.1). ${ }^{\mathrm{a}}$ Groups of OsPLD $\alpha 1$ variants based on amino acid sequences. ${ }^{\mathrm{b}} \mathrm{Groups}$ of $O s P L D \alpha 1$ variants based on nucleotide sequences. ${ }^{c}$ Ref indicate the nucleotide sequences variants which translates into the amino acid sequence same as that of the reference OsPLD $\alpha 1$ protein sequence of Nipponbare.

Nipponbare (Fig. 4a) and IR101152 accession of O. officinalis (Fig. 4b). RMSD (Root Mean Square Deviation) values were calculated using chimera and were found to be less than $2 \AA$ ( $0.745 \AA$ for Nipponbare and $0.825 \AA$ for IR101152) indicating the accuracy of generated structures. Further, the predicted structures were superimposed and results showed the absence of two $\beta$-sheets in the IR101152 accession of O. officinalis species (Fig. 4c).

Differential expression of OsPLD $\alpha 1$ variants. From each of the identified OsPLD 1 variants, at least one accession was selected for expression profiling. Significant differences were observed for the OsPLD 1 transcript levels in immature seeds from wild Oryza species accessions (Fig. 5). Expression differences for the transcripts acquired with primers designed from $5^{\prime}$ and $3^{\prime}$ ends of the second exon, signified the presence of truncated splice forms in most of the accessions. In addition, expression study also revealed significant expression variations between the genotypes for the same transcript variant and within the same genotype for different transcript variants. Further, for the confirmation of these results, amplification of full length transcript (Os01t0172400-1) and two alternate splice forms viz. Os01t0172400-4 and Os01t0172400-5 was performed in Oryza species accessions. Single sharp bands of expected amplicon size were obtained for all the three transcript forms (see Supplementary Figure S6), which validates that the full length as well as other transcripts with shorter lengths were present in the accessions. Moreover, it varified that the truncations obtained in the accessions are real and not due to failure of cDNA synthesis at the ends of mRNA. Of all the OsPLD $\alpha 1$ variants, lowest transcript expression (for all the four qRT-primers) was observed in the O. officinalis accession (IR101152) followed by O. punctata (IR101434). Further, the hierarchical clustering dendrogram represents the OsPLD 1 transcripts differences between as well as within the wild species accessions (Fig. 6). 

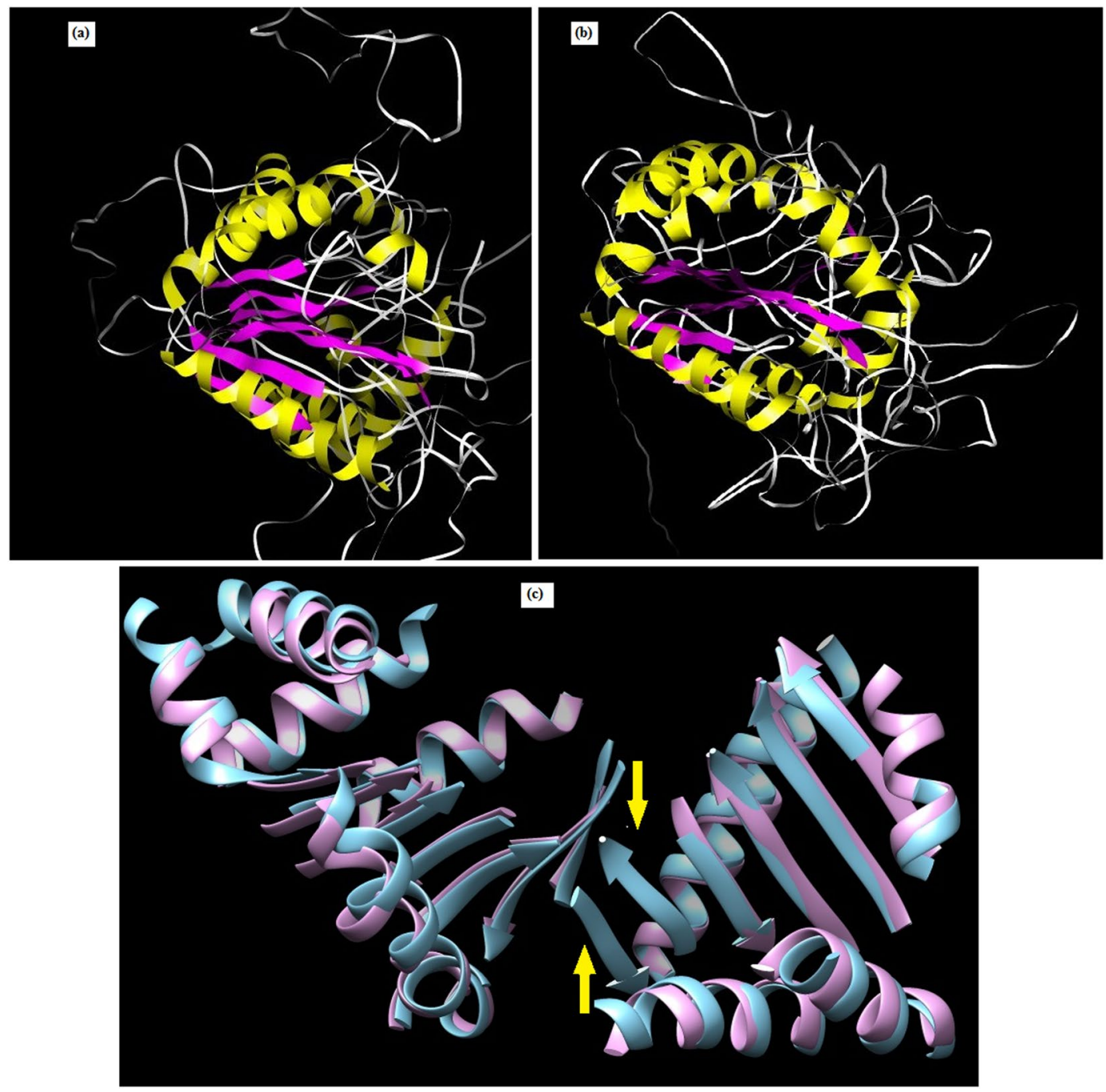

Figure 4. Three-dimensional structures of OsPLD $\alpha 1$ protein in (a) Nipponbare and (b) IR101152 accession of O. officinalis. (c) Superimposition of OsPLD $\alpha 1$ protein from Nipponbare and IR101152 accession of $O$. officinalis. Two $\beta$-strands (shown with arrows) were found missing in the IR101152 (depicted in pink color) upon superimposition with Nipponbare (depicted in blue color).

\section{Discussion}

The major bottleneck in improving the rice bran quality is narrow genetic base of germplasm on which breeders are working. Hence, the utilization of wild species germplasm to identify the 'novel alleles' through sequence based allele mining, and their further transfer to the elite lines has emerged as a good breeding strategy ${ }^{36}$. The progenitor Oryza species, in comparison to cultivated rice, are known to carry a number of functionally characterized genes with important coding variations ${ }^{37}$. It leads to the inference that useful coding variations for $O s P L D \alpha 1$ could be mined from primary and secondary Oryza gene pools. The present study depicts an in-depth survey of the genetic variability at $\operatorname{Os} P L D \alpha 1$ in a large panel of genetically and geographically diverse wild rice germplasm. Despite repeated efforts to sequence the second intron in the accessions belonging to genomes other than AA genome, we could not obtain high quality sequence and only multiplets were obtained in that region. The reason for this could be significant sequence differences between the reference japonica variety Nipponbare and the species with genomes other than AA genome species. This resulted in fragmented assembly of OsPLD 1 gene sequence in wild species having CC, EE, BBCC, and CCDD genomes and hence polymorphic and phylogenetic analysis were conducted for individual exons, introns and UTRs to include all the wild species accessions in the study.

Phylogenetic relationships of OsPLD 1 gene among diverese wild species germplasm of rice. At exon 1, only two distinguished clusters were observed comprising all the AA genome species in one cluster and other diploid and tetraploid genome species in other cluster (Fig. 1a). The probable explanation for the lower variability is the smaller size of the first exon as compared to other two exons and might have fewer roles in controlling the trait. Among the AA genome species, O. glaberrima accessions were found closely related to $O$. barthii accessions while O. rufipogon accessions clustered close to O. sativa and O. nivara. It has been already 


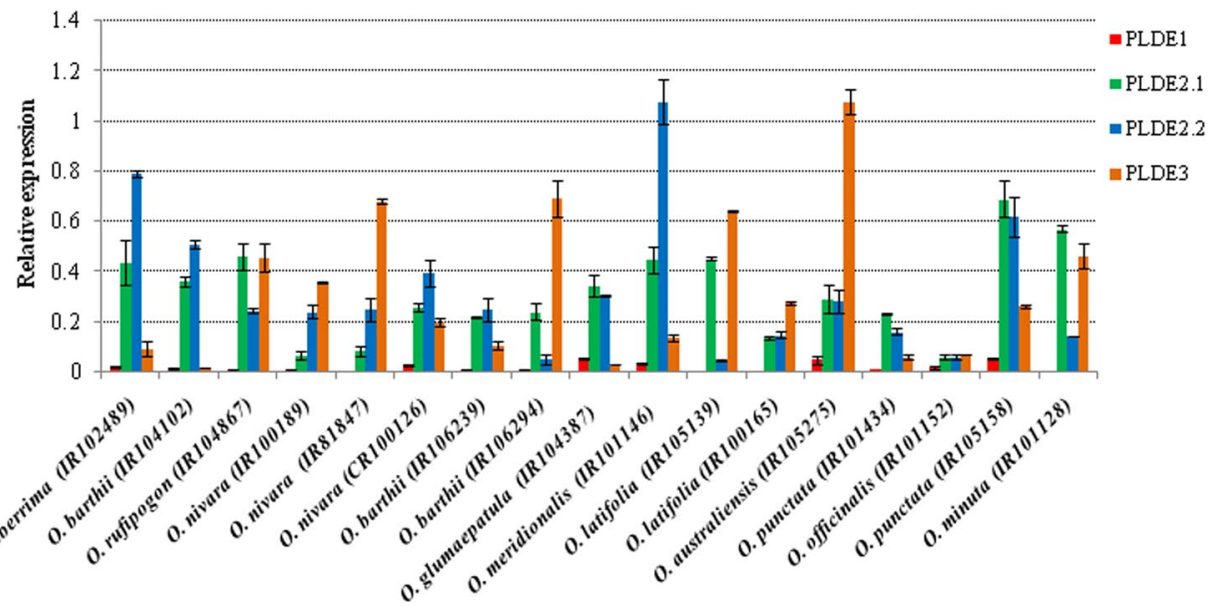

Wild Onza species accessions

Figure 5. OsPLD $\alpha 1$ transcript levels in immature seeds from wild Oryza species accessions. Mean values for $O S P L D \alpha 1$ transcripts and standard deviation (S.D.) measured relative to Actin expression. Relative transcript levels of OsPLD 1 , in accessions of wild Oryza species, for four qRT-PCR primers namely PLDE1 (designed from first exon of the gene), PLDE2.1 (designed from 5' end of second exon), PLDE2.2 (designed from $3^{\prime}$ end of second exon), and PLDE3 (designed from third exon of the gene) are shown. Among all the wild species accessions, IR101152 accession of O. officinalis was found to have lowest transcript levels using all the four qRTPCR primers.

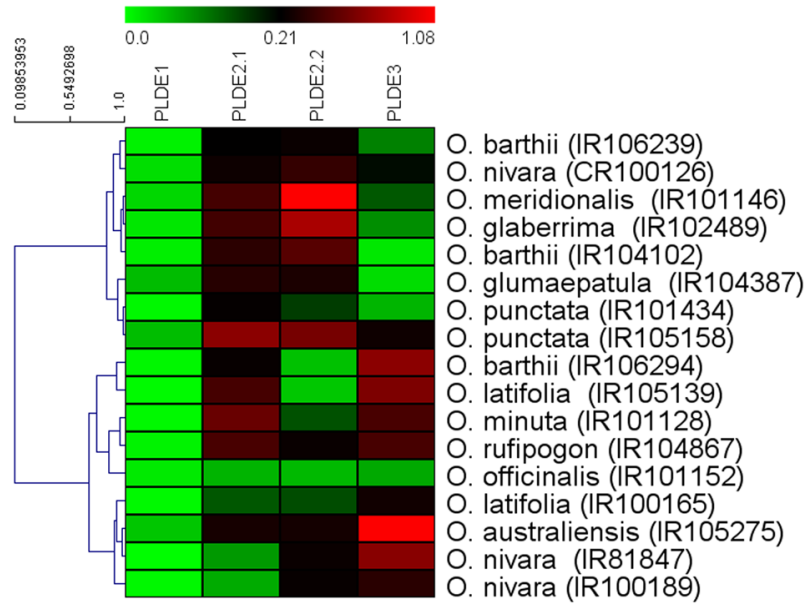

Figure 6. Heatmap showing differential expression of $O s P L D \alpha 1$ transcripts between as well as within the accessions of wild Oryza species. PLDE1, PLDE2.1, PLDE2.2 and PLDE3 denotes the qRT-primers designed from exons of $O s P L D \alpha 1$ gene. Wild species accessions (horizontal) were hierarchially clustered (Pearson sorrelation, average linkage). Color patterns from green to red indicate low to high transcript levels, thus IRGC101152 have the lowest expression for all the four exon specific qRT primers.

established by earlier studies that African rice O. glaberrima was domesticated from the wild progenitor O. barthii approximately 3,000 years ago ${ }^{38}$ explaining the relative closeness between the clads. Also, the close genetic relationship between African rice O. glaberrima and $O$. barthii has been inferred way back using isozymes as mark$\mathrm{ers}^{39}$ and later by using SSRs and SNPs markers ${ }^{40,41}$. A comparison at major domesticated genes, for instance, Gn1a (Grain productivity), qSH1 (Shattering), Sd1 (Semi-dwarfing), Gw2 (Grain width), GIF1 (Grain incomplete filling), badh2 (Flavor or fragrance), Phr1 (Grain discoloration), OsLG1 (Closed panicle), Sh4 (Shattering), Moc1 (Tillering), Rc (Red pericarp), Sdr4 (Seed dormancy), Ep2 (Erect panicle), Ipa1 (Ideal plant architecture), Dep1 (Panicle architecture), and Sh4 (Shattering) by Wang et al. ${ }^{42}$ revealed reduced nucleotide diversity in O. glaberrima than $O$. barthii which correlates well with the hypothesis of $O$. barthii being the progenitor harbors greater diversity and during the process of domestication/selection it got reduced in O. glaberrima. At two other exons of OsPLD 1 1, O. rufipogon and O. nivara accessions showed admixture among them as well as with O. sativa (indica as well as japonica) with not much divergence (Fig. 1b,c). This observation could be ascribed to the fact that these two wild species are more closely related and collectively regarded as the progenitors of O. sativa ${ }^{43,44}$. Extensive 
allele sharing between $O$. rufipogon and O. nivara has also been documented by Banaticla-Hilario et al. ${ }^{45}$. A taxonomic debate is still continued over whether O. rufipogon (the perennial species), O. nivara (the annual species), can be considered as two species or ecotypes of the same species ${ }^{46,47}$. Moreover, both O. rufipogon and $O$. nivara share a common geographical distribution in South and Southeast Asia therefore the probability of gene flow is higher between them. These species are cross compatible and exhibit little genetic differentiation and is supported by molecular phylogenetic analysis and population studies ${ }^{48-54}$.

At exon 2 and 3, the O. longistaminata accessions (distributed in Africa) consistently showed significant differentiation from other AA genome Oryza species. This divergence of O. longistaminata could be attributed to the unique morphological features such as self-incompatibility, distinctive characteristics of ligules and the presence of rhizomes. These features are not present in any other Oryza species which support to the data we obtained $^{55-57}$. Further, haplotype diversity and feature-specific variation has been reported in O. longistaminata which the authors attributed to out-crossing nature of this species ${ }^{58}$. The other explanation could be the long distance dispersal of the seeds by animals, birds or any other way followed by ecological differentiation making this species different. The comparative study of genetic relationship using SSR and RAPD markers also revealed clear differentiation of $O$. longistaminata from other AA genome species ${ }^{59}$. Similar observations were also found by other scientists ${ }^{60-62}$. Interestingly, O. meridinolis did not group with any of the AA genome cluster. These results are consistent with the findings of evolutionary divergence study at PSTOL1 locus in wild, domesticated and weedy rice ${ }^{63}$ but contradictory to the findings based on plastome analysis which shows O. longistaminata to be most diverged from AA-species ${ }^{64}$.

The present study revealed that the species belonging to the O. officinalis complex (O. officinalis, O. australiensis, O. punctata, O. minuta, and O. latifolia) harbor maximum variability at the OSPLD $\alpha 1$ locus in comparison to AA genome spp. and Oryza cultivars. This complex is the largest one with 10 species and five genome types (BB, CC, EE, BBCC, CCDD) that are distributed widely in Asia, Africa, Australia and Latin America ${ }^{65}$, and hence might be capturing wider variability due to ecological speciation and polyploidization events. It is noteworthy that the O. officinalis (CC genome) accessions formed a distinct cluster at second and third exons then the counter diploid species O. punctata (BB genome) and two of the tetraploid species O. minuta (BBCC) and O. latifolia (CCDD) (Fig. 1b,c). These results signify that the O. officinalis species carry maximum variability at the OsPLD 1 locus in comparison to rest of the Oryza species. A study on polyploidy evolution in O. officinalis complex by Wang et al. (2009) states that the CC genome diverges with BB genome at ca.4.8 Mya followed by a series of speciation of $\mathrm{C}$ genome diploids and later successive events of polyploidization leads to the formation of tetraploid species i.e CCDD at 0.9 Mya and BBCC between ca. 0.3-0.6 Mya ${ }^{66}$. Further, O. latifolia (CCDD genome) clustered closer to O. australiensis (EE), this can be explained by the fact that EE genome is considered to be progenitor of DD genome ${ }^{67-69}$. Allele mining at Pi54 locus by Kumari et al. (2013) also observed that O. officinalis, O. punctata and $O$. latifolia forms a divergent cluster from other AA genome species ${ }^{70}$. A comparison of the sequences of Xa3/ $X a 26$ orthologous family also revealed very low similarity between cultivated rice and wild Oryza species comprising of O. officinalis and O. minuta ${ }^{71}$.

In addition to the variations in coding region of the $O s P L D \alpha 1$ gene, the nucleotide changes including large InDels were also detected in the non-coding regions including first and third introns. Contrary to the other genome species, all the AA genome species were found in the same clade as of the Nipponbare, and O. meridionalis was found most distantly related of all the AA genome species (Fig. 2a,c). The Oryza officinalis complex, in a similar fashion of carrying maximum variability in the coding region, was found to carry maximum variability in the non-coding region as well. These variations included SNPs as well as large InDels (see Supplementary Table S2). The roles of intronic mutations have earlier been found evident in the expressions of tubulin, polyubiquitin and waxy $(W x)$ genes of rice ${ }^{72-74}$. The variations detected, in the current study, at the non-coding region of $O s P L D \alpha 1$ could play significant role in the transcript synthesis and accumulation which might lead to change in trait expression.

Protein domain analysis in OsPLD $\alpha 1$ variants. In this study, domains and motifs of the Nipponbare OsPLD $\alpha 1$ protein were aligned with the protein sequence of 12 OsPLD $\alpha 1$ variants (see Supplementary Fig. S7). Rice OsPLD $\alpha 1$ contains a single putative $\mathrm{C} 2$ domain that has been predicted to be involved in signal transduction and membrane trafficking, and is important in $\mathrm{Ca}^{2+}$-regulated binding to phospholipids ${ }^{75,76}$. In plants, $\mathrm{Ca}^{2+}$ is an important regulator of PLD activity, C2 domain has been known to play an important role in this regulation ${ }^{77,78}$. In the present study, seven of the identified protein variants viz. VI, VII, VIII, IX, X, XI, and XII were found to have a deletion of 17 amino acid long peptide that also included one of the four conserved amino acids (Glutamic acid at position 42) that are instrumental in $\mathrm{Ca}^{2+}$ binding ${ }^{79}$. The variants VIII, IX, X, XI and XII were having a common amino acid substitution at the position 111. In addition, variant $\mathrm{X}$ was detected with two unique amino acid substitutions in the C2 domain, at positions 59 and 60. The missing peptide, absence of conserved amino acid, and amino acid substitutions, may further lead to change in the protein function as this domain is important in translocating proteins to memberanes ${ }^{80,81}$. C2 domain deletion mutants in PI3K lead to loss of important inter-residue contacts and thereby lead to reduction in binding energy ${ }^{82}$. Downstream of the C2 domain, B-domain was found conserved among all the 12 protein varaints except for a single amino acid substitution in the varaint III. This region is similar to the B-domain of insect and cereal $\alpha$-amylases that frequently regulate enzyme activity ${ }^{83-85}$.

Each rice PLD consists of two fully conserved HxKxxxxD motifs, which form the active catalytic site for phosphoester bond hydrolysis ${ }^{86}$. Any mutation in the HKD motifs abolishes the enzymatic activity of the PLD enzyme. Our inspection of predicted protein sequences revealed the presence of both of the HKD motifs in all the protein variants (see Supplementary Fig. S7) which is supported by the fact that most eukaryotic PLDs require two functional HKD sites to remain catalytically active ${ }^{87}$. Also, the three amino acid residues involved in PIP $_{2}$ activation were found conserved in all the variants ${ }^{88}$. However, within the first PLD catalytic (PLDc-I) motif of the 
Os01t0172400-06 (Transcript variant)

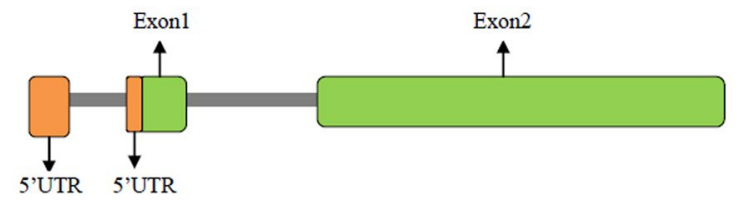

Figure 7. Graphical representation of newly identified OsPLD $\alpha 1$ transcript variant, Os01t0172400-06. A new transcript form having only two exons was detected in the wild Oryza species accessions viz. O. barthii (IR104102 and IR106239), O. nivara (CR100126), O. glaumaepatula (IR104387), O. meridionalis (IR101146), and O. punctata (IR101434 and IR105158); and an accession of O. glaberrima (IR102489). Expression profiling in these accessions, using exon specific qRT-PCR primers, showed the low abundance of transcripts having third exon.

variant X, 15 amino acid long peptide was missing (see Supplementary Fig. S5) which might also had an altered effect on the enzyme activity.

OsPLD $\alpha 1$ gene expression profiling in Wild Oryza species and detection of a new OsPLD 1 transcript. To carry out expression analysis at $O S P L D \alpha 1$ locus, the plant development stage for RNA extraction was chosen on the basis of expression profiling of 17 PLD isoforms using the expression data from RiceXProv3.0 database (see Supplementary Fig. S8). The expression analysis using various plant tissues at different developmental stages indicated that the activity of $O s P L D \alpha 1$ enzyme was very high during early stages of grain development. Moreover, Suzuki (2011) reported the hike of PLD content in the seeds till 3 wk after flowering, becoming stagnant afterwards. Also, no PLD protein band was observed one week after flowering in the seeds of PLD-null rice mutant (03-s108), having $<0.01 \%$ PLD activity in rice bran when compared to Nipponbare ${ }^{21}$. These results correlate the functional expression of OsPLD $\alpha 1$ in rice bran and immature seeds. Consequently, for the experiments conducted in the current study, RNA was isolated from immature seeds (one week after flowering). The quantitative gene expression studies have been successfully utilized to study the alterations in the transcript abundance during cell differentiation or development ${ }^{89}$; variation in expression for cells vulnerable to a chemical substance, for instance, drug, toxin, hormone or cytokine) ${ }^{90}$; and as a diagnostic tool ${ }^{91}$.

For expression analysis, in the present study, four exon-specific qRT-PCR primer pairs were designed from the exonic region of $O s P L D \alpha 1$ (Table S3). The designed primers aimed to assess the wild genotypes for variability in the gene expression as well as to unveil if the gene is alternatively spliced (see Supplementary Fig. S9). Alternate splicing has been known to control the gene expression and functional diversification of proteins in higher eukaryotes. Alternative splicing of the $\mathrm{Ca}^{2+}$-independent phospholipase $\mathrm{A}_{2}\left(\mathrm{iPLA}_{2}\right)$ pre-mRNA in humans can result in the production of regulatory subunits that can modify $\mathrm{iPLA}_{2}$ in vivo activity ${ }^{2}$. Alternative splicing is ubiquitous in rice with 36,650 known splicing events effecting 8772 genes including OsWRKY62 and OsWRKY76 $6^{93,94}$. Further, differential expression levels of various genes involved in spikelet development in different rice species have been shown to manifest different phenotypes ${ }^{95}$. Our expression profiling results revealed significant differences in the $O s P L D \alpha 1$ transcript abundance, between the wild Oryza species, being lowest in O. officinalis spp. followed by $O$. punctata and O. latifolia (Fig. 5). In the O. officinalis accessions, two insertions viz. A at nucleotide position 459 and $\mathrm{T}$ at nucleotide position 1927 led to maximum alterations in the OsPLD $\alpha 1$ protein that included 14 amino acid substitutions and absence of two peptides (see Supplementary Fig. S4 and S5). The alterations observed in the protein could be the reason for lowest enzymatic activity in O. officinalis spp. The novel allele leading to low OsPLD $\alpha 1$ expression in O. officinalis accessions has been named as OsPLD $\alpha 1-1 a$ and is available in NCBI database (http://www.ncbi.nlm.nih.gov) with GenBank accession numbers MF966931, MF966932, and MF966933. In addition, significant differences were observed in the transcript abundance within the accessions for the primers designed from $5^{\prime}$ and $3^{\prime}$ ends of second exon, demonstrating the presence of $5^{\prime}$ and $3^{\prime}$ truncated mRNA (Fig. 5). Interestingly, IR102489 accession of O. glaberrima and accessions of wild Oryza species including O. barthii (IR104102 and IR106239), O. nivara (CR100126), O. glaumaepatula (IR104387), O. meridionalis (IR101146), and O. punctata (IR101434 and IR105158) had low abundance of transcripts having third exon when compared to the transcript levels of the first and second exons (Fig. 5). However, the five earlier reported OsPLD $\alpha 1$ transcript forms confirm the presence of third exon in all the splice forms (see Supplementary Fig. S9). Therefore, the current study revealed the presence of a new OsPLD $\alpha 1$ transcript variant, named as Os01t0172400-06, having truncations before the third exon (Fig. 7).

\section{Conclusion}

The species belonging to $O$. officinalis complex possess maximum variability at the OsPLD $\alpha 1$ locus. Of the $O$. officinalis complex species, OsPLD 1 allele of $O$. officinalis accessions has been reported to carry maximum number of non-synonymous SNPs/InDels which further led to alterations in the protein domains, that are responsible for regulating the enzyme activity. The lowest levels of $O s P L D \alpha 1$ transcript abundance in the O. officinalis accessions suggests that the reported polymorphism in the nucleotide and amino acid sequences, varied gene structure, and altered domains play an important role in regulating the enzyme activity in rice bran. Also, a new 


\begin{tabular}{|l|l|l|l|}
\hline Primer ID & Forward Primer $\left(\mathbf{5}^{\prime}\right.$ to $\left.\mathbf{3}^{\prime}\right)$ & Reverse $^{\prime}$ Primer $\left(\mathbf{5}^{\prime}\right.$ to $\left.\mathbf{3}^{\prime}\right)$ & Amplicon size $^{\mathbf{a}}$ \\
\hline PLD-1 & TTTAACCTCGCCTCCTCC & TCTCCAATTCTTGTCTACTACC & 783 bases $(-154-629)$ \\
\hline PLD-2 & GCCCGAATTTGATCTGCT & TTTGGAATGAAGTTGTCTGG & 946 bases $(545-1472)$ \\
\hline PLD-3 & GGAGAGGAGATTGACAGATGG & AGGAGAAGGTGGAATAATAGTG & 995 bases $(1259-2233)$ \\
\hline PLD-4 & CATGATATTCACTCACGGCT & TGTAACTCATCTGACATGCT & 862 bases $(2114-2957)$ \\
\hline PLD-5 & CTACCTCACTTTCTTCTGCT & ATGTCCCAGTACTTCTCC & 885 bases $(2749-+16)$ \\
\hline
\end{tabular}

Table 4. Overlapping PCR-primer pairs used for amplification of different segments of the OsPLD $\alpha 1$. ${ }^{a}$ Numbers in parenthesis shows the position of bases covered by the primer pairs on OSPLD $\alpha 1$ locus.

OsPLD $\alpha 1$ transcript variant named as Os01t0172400-06, having third exon missing in it, was discovered in the present study. We are in the process of transferring the superior OsPLD 1 allele, identified in $O$. officinalis accession (IRGC101152) i.e., OsPLD $\alpha 1-1 a$ (GenBank accession no. MF966931), into the elite rice cultivars.

\section{Methods}

Plant materials. A set of 56 accessions including 48 accessions representing 11 wild species of Oryza viz. $O$. barthii $(\mathrm{n}=6)$, O. nivara $(\mathrm{n}=10)$, O. rufipogon $(\mathrm{n}=16)$, O. longistaminata $(\mathrm{n}=3)$, O. meridionalis $(\mathrm{n}=1), O$. glumaepatula $(\mathrm{n}=2)$, O. officinalis $(\mathrm{n}=3)$, O. australiensis $(\mathrm{n}=1)$, O. punctata $(\mathrm{n}=2)$, O. minuta $(\mathrm{n}=2)$, and $O$. latifolia $(\mathrm{n}=2)$ ]; and 8 accessions of African cultivated rice $O$. glaberrima were undertaken for the current study (Table 1). These germplasm accessions have been actively maintained at Punjab Agricultural University (PAU), Ludhiana, and were originally procured from the International Rice Research Institute (IRRI), Philippines and from National Rice Research Institute (NRRI), Cuttack. The sequence analysis in Oryza cultivars namely Punjab Rice 114 (PR 114), Nagina 22 (N22), IR64, Pusa 44, Minghui 63, Feng-Ai-Zhan, and Kitake, revealed the presence of $O s P L D \alpha 1$ allele. Therefore, these cultivars were used as positive checks to carry out the comparative OsPLD 1 sequence analysis with wild Oryza species accessions. Standard agronomic practices were followed to raise the crop. These practices included sowing of seeds in seedbeds and transplanting one-month-old seedlings in the field with a row-to-row distance of $70 \mathrm{~cm}$ and plant-to-plant distance of $45 \mathrm{~cm}$; weed control using a Paddy Weeder, 15 days after transplanting and again after a fortnight; application of organic manures ( 15 tonnes of farmyard manure per hectare prior to transplanting of rice), bio-fertilizer (treat the nursery seedlings for 45 minutes in the solution made by dissolving $0.5 \mathrm{~kg}$ of Azorhizobium biofertilizer in requisite amount of water so as to soak seedlings needed to transplant one hectare, and then transplanting was done immediately) along with chemical fertilizers comprising $222 \mathrm{~kg} / \mathrm{ha}$ Neem coated urea (provide $104 \mathrm{~kg} / \mathrm{ha}$ Nitrogen), $67 \mathrm{~kg} / \mathrm{ha}$ Diammonium Phosphate (provide $30 \mathrm{~kg} / \mathrm{ha}$ phosphorus), and $49 \mathrm{~kg} / \mathrm{ha}$ Muriate of potash (provide $30 \mathrm{~kg} / \mathrm{ha}$ potassium) for higher crop yield and maintenance of soil health. 1/3 nitrogen was applied within 2 weeks of transplanting while the whole phosphorus and potassium was applied before the last puddling. Broadcasting of the remaining nitrogen was done in two equal splits, one three weeks after transplanting and the other three weeks afterwards; water was kept standing in the crop continuously for two weeks after transplanting, and thereafter irrigation was done two days after the ponded water has infiltrated into the soil; to facilitate harvesting, irrigation was stopped about a fortnight before maturity; panicles of the plants were covered with the mash bags to avoid shattering of the seeds; harvesting and threshing of different genotypes was done separately to avoid seed admixture.

DNA extraction, primer designing and PCR amplification. The current study followed a modified $\mathrm{CTAB}$ method to isolate genomic DNA from the selected genotypes ${ }^{96} .0 .8 \%$ agarose gel was used to access the quantity and quality of DNA from each sample. For further use, DNA samples were diluted with 1X TE buffer and stored at $-20^{\circ} \mathrm{C}$. To PCR amplify the coding and non-coding regions of the OsPLD 1 variants, Oryza sativa japonica cv. Nipponbare sequence (GenBank accession no. AB571657.1) was utilized to design five overlapping primer pairs (Table 4). Supplementary Fig. S10 shows the OsPLD 1 gene structure (RAPdb ID Os01g0172400) and positions of the designed primer pairs along the length of gene. First and last primers were designed from the upstream and downstream flanking regions of the gene to sequence the whole gene. PCR was performed in a 30 $\mu \mathrm{l}$ reaction mix containing $0.3 \mu \mathrm{l}$ Phusion ${ }^{\circledR}$ high fidelity DNA polymerase, $3 \mu \mathrm{l}$ of genomic DNA (20ng/ $\left.\mu \mathrm{l}\right), 6 \mu \mathrm{l}$ of $5 \mathrm{X}$ HF buffer, $6 \mu \mathrm{l}$ of dNTPs $(1 \mathrm{mM}), 3 \mu \mathrm{l}$ of primer $(5 \mu \mathrm{M})$, and $11.7 \mu \mathrm{l}$ Nuclease Free Water. The thermal cycling conditions were as follows: an initial denaturation at $94^{\circ} \mathrm{C}$ for $5 \mathrm{~min} ; 35$ cycles of $1 \mathrm{~min}$ denaturation at $94^{\circ} \mathrm{C}$ followed by $1 \mathrm{~min}$ annealing at $55^{\circ} \mathrm{C}$ and $1 \mathrm{~min}$ extension at $72^{\circ} \mathrm{C}$; and a final 5 min extension at $72^{\circ} \mathrm{C}$.

Sequencing of $O s P L D \alpha 1$ gene in selected accessions and cultivars. Ethidium bromide stained $1.0 \%$ agarose gel electrophoresis was performed to analyze PCR products. $1 \mathrm{~kb}$ plus ladder (Thermo Scientific Generular) was used to estimate the DNA fragment size. We obtained single sharp bands of expected amplicon size for all the five overlapping primers (see Supplementary Fig. S11). The Wizard ${ }^{\circledR}$ SV PCR Clean-Up System (Promega, USA) as per the manufacturer's protocol was followed to excise and purify the DNA fragments. The details of targeted DNA nucleotide sequence were created using separate sequencing reactions for forward and reverse primers. The ABI Big-dye Terminator v3.1 chemistry performed the sequencing reaction and ABI Sequencer 3730XL sequenced the DNA fragments, at the School of Agricultural Biotechnology, Punjab Agricultural University, Ludhiana. Experiment was carried out in two replications to confirm the presence of single nucleotide polymorphism (SNPs). 
Analysis of the generated nucleotide sequences and protein prediction. For comparative sequence analysis, DNA Baser v4.23.0 (http://www.dnabaser.com/) software joined the contigs produced by overlapping primers, and generated the consensus sequence of $O s P L D \alpha 1$ gene. This software also helps in automatic identification and clipping of poor quality regions at both ends of the sequences. ClustalX 2.1.1 software was undertaken to generate the multiple sequence alignment ${ }^{97}$. OsPLD $\alpha 1$ sequence from 'Nipponbare' rice variety, which contains normal levels of PLD activity i.e., 133.2 units $/ \mathrm{mg}^{21}$, was used as reference (wild type) in this study. The identified SNPs and InDels were then manually curated by comparing chromatogram files to the ClustalX alignment files.

HMM-based FGENESH online program (http://www.softberry.com/berry.phtml?topic=fgenesh) was used to predict the gene structure and amino acid sequences in different genotypes which were further compared with the Nipponbare protein to detect amino acid substitutions and InDels. Pfam (http://pfam.xfam.org/) online program predicted the domains and motifs in the protein variants. Bioinformatics toolkit (http://toolkit.tuebingen.mpg.de/) was used to predict the tertiary structures of protein. The MODELLER Homology modeling approach was followed ${ }^{98}$ to determine the structure of proteins based on the known strucure of template protein. Ramachandran plots were developed using Procheck through PDBsum (http://www.ebi.ac.uk/thornton-srv/ databases/pdbsum) to check the quality of protein models. UCSF Chimera helped to visualize and compare the modeled protein structures ${ }^{99}$. All the developed tertiary structures were superimposed to detect the structural variations. Uniprot (http://www.uniprot.org/uniprot/P84147) online program determined the catalytic sites in the protein.

Phylogenetic analysis. The MEGA7 software ${ }^{100}$ was used to generate the phylogenetic tree using multiple sequence alignment file. The evolutionary distances were computed using the Maximum Composite Likelihood method with 1,000 bootstrap and are in the units of the number of base substitutions per site.

RNA isolation, CDNA synthesis, and expression analysis using qRT-PCR. To collect the RNA sample at the same stage (one week after flowering, at milking stage of grain development) from different wild species and cultivars, flowering data was collected on the daily basis. For each genotype, tissue for RNA isolation was collected in a way that each experimental replicate represents RNA from three biological replic ates ${ }^{101}$.

The TRIzol ${ }^{\circledR}$ reagent (Thermo Fisher Scientific) was used for RNA isolation according to the manufacturer's protocol. The expression analysis part of the study wa s done at the School of Biology and Ecology, University of Maine, Orono, USA. NanoDrop ${ }^{\circledR}$ ND-1000 estimated the RNA quantity for the different samples. We employed an iScript cDNA kit (Bio-Rad laboratories, CA, USA) which produces first strand cDNAs by reverse transcribing RNA. Sequences of OsPLD 1 loci and its transcript forms (Locus ID Os01g0172400), for qRT primers designing, were retrieved from RAP data base (http://rapdb.dna.affrc.go.jp/viewer/gbrowse/).

Using the Primer-BLAST tool (http://www.ncbi.nlm.nih.gov/tools/primer-blast/), four exon-specific qRT-primer pairs (PLDE1, PLDE2.1, PLDE2.2, and PLDE3) (see Supplementary Table S3) were designed from the exonic regions of OsPLD $\alpha 1$. qRT-primers were generated to assess the wild genotypes for variations in abundance of $O s P L D \alpha 1$ transcript variants (see Supplementary Fig. S9). Each primer was dissolved in $1 \mathrm{X}$ TE buffer (stock solution) to have a master stock of $100 \mu \mathrm{M}$. Real-time PCR was performed in $\mathrm{MyiQ}^{\mathrm{TM}}$ thermal cycler (Bio-Rad Laboratories, CA, USA) using the $\mathrm{iQ}^{\mathrm{TM}} \mathrm{SYBR}^{\circledR}$ Green Supermix (Bio-Rad) according to the manufacturers protocol. The cycling conditions were as follows: $95^{\circ} \mathrm{C}$ for $30 \mathrm{~s}, 40$ cycles of $95^{\circ} \mathrm{C}$ for $5 \mathrm{~s}$ and $60^{\circ} \mathrm{C}$ for $30 \mathrm{~s}$. Each sample was amplified in triplicate to confirm the results. $2^{-\Delta \mathrm{CT}}$ method was used to calculate the relative expression levels ${ }^{102}$, and the actin (Locus ID Os10g0510000) gene was used as an internal control to normalize the data. For validation of expression results, primers were designed for the full length amplification of three alternate splice forms viz., Os01t0172400-1, Os01t0172400-4 and Os01t0172400-5 (see Supplementary Table S4).

\section{Data availability}

The DNA sequences of wild species accessions and cultivars generated and analyzed during the current study are available in the GenBank repository with accession numbers: O. glaberrima [IRGC100854 (MF774061), IRGC101800 (MF919319), IRGC102196 (MF919320), IRGC102489 (MF919321), IRGC102512 (MF919322), IRGC102600b (MF919323), IRGC102925 (MF919324), IRGC103750 (MF919325)]; O. bartii [IRGC100117 (MF919326), IRGC101317 (MF919327), IRGC104102 (MF919328), IRGC105990 (MF919329), IRGC106239 (MF919330), IRGC106294 (MF919331)]; O. nivara [CR100008 (MF919334), CR100400 (MF919335), CR100429 (MF91336), IRGC80547 (MF919332), IRGC81847 (MG725633), IRGC92713 (MF919337), IRGC92930 (MG725634), IRGC100189 (MF919338), IRGC106397 (MF919333)]; O. rufipogon [CR100013 (MG725637), IRGC80610 (MG725635), IRGC81976 (MG725638), IRGC83823 (MG725640), IRGC89224 (MG725641), IRGC99551 (MG725642), IRGC103308 (MF919339), IRGC104308 (MG725643) IRGC104867 (MF966922), IRGC105491 (MG7256360), IRGC105569 (MF966923), IRGC105902 (MF966924), IRGC106162 (MF966925), IRGC106336 (MF966926), IRGC106433 (MF966927), IRGC113652 (MF966928)]; $O$. longistaminata [IRGC101200 (MG725645), IRGC104301 (MG725646), IRGC105206 (MG725647)]; O. meridionalis [IRGC101146 (MG725648)]; O. glumaepatula [IRGC100184 (MF966930), IRGC104387 (MF966929)]; O. officinalis [IRGC101152 (MF966931), IRGC105674 (MF966932), IRGC106501 (MF966933)]; O. australiensis [IRGC105275 (MG725650)]; O. punctata [IRGC105158 (MG725651)]; O. minuta [IRGC101100 (MG725652), IRGC101128 (MG725653)]; O. latifolia [IRGC105139 (MG725654)]; Feng-Ai-Zhan (MF975521); Kitake (MF975522); Minghui63 (MF975523); Nagina22 (MF975524); PR114 (MF975525); Pusa44 (MF975526).

Received: 11 September 2018; Accepted: 16 March 2020;

Published online: 20 April 2020 


\section{References}

1. Hargrove, K. L. Processing and utilization of rice bran in the United States. Rice Science and Technology. Marshall, W. E. and Wadsworth, J. I. (Eds.). New York: Marcel Dekker Inc. (1994).

2. Hu, W., Wells, J. H., Shin, T. S. \& Godber, J. S. Comparison of isopropanol and hexane for extraction of vitamin E and oryzanols from stabilized rice bran. J. Am. Oil Chem. Soci. 73, 1653-1656 (1996).

3. Saunders, R. M. The properties of rice bran as a foodstuff. Cereal Foods World 35, 632-636 (1990).

4. Yoshino, G. Effects of $\gamma$-oryzanol on hyperlipidemic subjects. Current Therapy Res. 45, 543-552 (1989).

5. Krishna, A. G. G., Khatoon, S. \& Babylatha, R. Frying performance of processed rice bran oils. J. Food Lipids 12, 1-11 (2005).

6. Nicolosi, R. J., Ausman, L. M. \& Hegsted, D. M. Rice bran oil lowers serum total and low density lipoprotein cholesterol and apo B levels in nonhuman primates. Atherosclerosis 88, 133-142 (1991).

7. Salunkhe, D. K., Chavan, J. K., Adsule, R. N. \& Kadam, S. S. Rice in World oilseeds: Chemistry, technology, and utilization. New York: Van Nostrand Reinhold. pp. 424-428 (1992).

8. Takano, K., Kamoi, I. \& Obara, T. Changes in lipid components and lipolytic enzyme activities of rice bran during storage (Studies on the mechanisms of lipids-hydrolysing in rice bran part I). J. Jpn. Soc. Food Sci. Technol. 33, 310-315 (1986).

9. Barnes, P. and Galliard, T. Rancidity in cereal products. Lipid Technol. 3, 23-28 (1991).

10. List, G. R., Mounts, T. L. \& Lanser, A. C. Factors promoting the formation of nonhydratable soybean phosphatides. J. Am. Oil Chem. Soc. 69, 403-410 (1992).

11. Nakayama, Y., Saio, K. \& Kito, M. Decomposition of phospholipids in soybean during storage. Cereal Chem. 58, 260-264 (1981).

12. Takano, K., Kamoi, I. \& Obara, T. Purification and properties of rice bran phospholipase D. J. Jpn. Soc. Food Sci. Technol. 34, 8-13 (1987).

13. Takano, K., Kamoi, I. \& Obara, T. Properties and degradation of rice bran spherosome. J. Jpn. Soc. Food Sci. Technol. 36, 468-474 (1989).

14. Suzuki, Y. et al. Volatile components in stored rice [Oryza sativa (L.)] of varieties with and without lipoxygenase-3 in seeds. J. Agric. Food Chem. 47, 1119-1124 (1999).

15. Zhou, Z., Robards, K., Helliwell, S. \& Blanchard, C. Ageing of stored rice: Changes in chemical and physical attributes. J. Cereal Sci. 35, 65-78 (2002).

16. Gang, L., Fang, L. \& Hong-Wei, X. Genome-wide analysis of the phospholipase D family in Oryza sativa and functional characterization of $P L D \beta 1$ in seed germination. Cell Res. 17, 881-894 (2007).

17. Qin, C. \& Wang, X. The Arabidopsis phospholipase D family: characterization of a $\mathrm{Ca}^{2+}$-independent and phosphatidylcholineselective PLD $\zeta 1$ with distinct regulatory domains. Plant Physiol 128, 1057-1068 (2002).

18. Ueki, J., Morioka, S., Komari, T. \& Kumashiro, T. Purification and characterization of phospholipase D (PLD) from rice (Oryza sativa L.) and cloning of cDNA for PLD from rice and maize (Zea mays L.). Plant Cell Physiol. 36, 903-914 (1995).

19. Suzuki, Y., Takeuchi, Y. \& Shirasawa, K. Identification of a seed phospholipase D null allele in rice (Oryza sativa L.) and development of SNP markers for phospholipase D deficiency. Crop Sci. 51, 2113-2118 (2011).

20. Sato, Y. et al. RiceXPro: a platform for monitoring gene expression in japonica rice grown under natural field conditions. Nucleic Acids Res. 39, 1141-1148 (2011)

21. Suzuki, Y. Isolation and characterization of a rice (Oryza sativa L.) mutant deficient in seed phospholipase D, an enzyme involved in the degradation of oil-body membranes. Crop Sci. 51, 567-573 (2011).

22. Ramezanzadeh, F. M., Rao, R. M., Windhauser, M., Prinyawiwatkul, W. \& Marshall, W. E. Prevention of hydrolytic rancidity in rice bran during storage. J. Agric. Food Chem. 47, 2997-3000 (1999).

23. Malekian, F. et al. In: Lipase and lipoxygenase activity, functionality, and nutrient losses in rice bran during storage: Bull 870 . Louisiana Agric Exp Stn: LSU Agric Cent, Baton Rouge, LA. pp 1-56 (2000).

24. McCaskill, D. R. \& Zhang, F. Use of rice bran oil in foods. Food Technol. 53, 50-53 (1999).

25. Doebley, J. F., Gaut, B. S. \& Smith, B. D. The molecular genetics of crop domestication. Cell 127, 1309-1321 (2006).

26. Khush, G. S. \& Ling, K. C. Inheritance of resistance to grassy stunt virus and its vector in rice. J. Hered. 65, 135-136 (1974).

27. Amante-Bordeos, A. et al. Transfer of bacterial blight and blast resistance from the tetraploid wild rice Oryza minuta to cultivated rice (Oryza sativa). Theor. Appl. Genet. 84, 345-354 (2002).

28. Amarawathi, Y. et al. Mapping of quantitative trait loci for basmati quality traits in rice (Oryza sativa L.). Mol. Breed. 21, 49-65 (2008).

29. Saitoh, K., Onishi, K., Mikami, I., Thidar, K. \& Sano, Y. Allelic diversification at the C (OsC1) locus of wild and cultivated rice: nucleotide changes associated with phenotypes. Genetics 168, 997-1007 (2004).

30. Wang, X., Jia, Y., Shu, Q. Y. \& Wu, D. Haplotype diversity at the Pi-ta locus in cultivated rice and its wild relatives. Phytopath. 98, 1305-1311 (2008).

31. Yang, S. et al. Genetic variation of NBS-LRR class resistance genes in rice lines. Theor. Appl. Genet. 116, 165-177 (2008).

32. Yoshida, K. \& Miyashita, N. T. Nucleotide polymorphism in the Adh2 region of the wild rice Oryza rufipogon. Theor. Appl. Genet. 111, 1215-1228 (2005).

33. Mikami, I. et al. Allelic diversification at the $w x$ locus in landraces of Asian rice. Theor. Appl. Genet. 116, 979-989 (2008).

34. Brooks, S. A., Yan, W., Jackson, A. K. \& Deren, C. W. A natural mutation in $r c$ reverts white rice pericarp to red and results in a new, dominant, wild-type allele: Rc-g. Theor. Appl. Genet. 117, 575-580 (2008).

35. Leiros, I., Secundo, F., Zambonelli, C., Servi, S. \& Edward, H. The first crystal structure of a phospholipase D. Structure 8, 655-667 (2000).

36. Kumar, G. R. et al. Allele mining in Crops: prospects and potentials. Biotechnol. Adv. 28, 451-461 (2010).

37. Zhao, Q. et al. Pan-genome analysis highlights the extent of genomic variation in cultivated and wild rice. Nature genetics 50, 278-284 (2018)

38. Sweeny, M. \& McCouch, S. The complex history of the domestication of rice. Ann. Bot. 100, 951-957 (2007).

39. Second, G. Origin of the genic diversity of cultivated rice growing environment in West Africa. (Oryza spp.): Study of the polymorphism scored at 40 isozyme loci. Japanese. Journal of Genetics 57, 25-57 (1982).

40. Semon, M., Nielsen, R., Jones, M. P. \& McCouch, S. R. The population structure of African cultivated rice Oryza glaberrima (Steud.): evidence for elevated levels of linkage disequilibrium caused by admixture with $O$. sativa and ecological adaptation. Genetics 169, 1639-1647 (2005).

41. Meyer, R. S. et al. Domestication history and geographical adaptation inferred from a SNP map of African rice. Nature Genetics; https://doi.org/10.1038/ng.3633 (2016).

42. Wang, M. et al. The genome sequence of African rice (Oryza glaberrima) and evidence for independent domestication. Nature genetics 46, 982-988 (2014).

43. Sang, T. \& Ge, S. Understanding rice domestication and implications for cultivar improvement. Curr. Opin. Plant. Biol. 16, 139-146 (2013).

44. Vaughan, D. A., Lu, B. R. \& Tomooka, N. The evolving story of rice evolution. Plant Sci. 174, 394-408 (2008).

45. Banaticla-Hilario, M. C. N., van den Berg, R. G., Hamilton, N. R. S. \& McNally, K. L. Local differentiation amidst extensive allele sharing in Oryza nivara and O. rufipogon. Ecology and Evolution 3, 3047-3062 (2013).

46. Morishima, H. Evolution and domestication of rice. Rice Genetics IV, IRRI. pp 63-78 (2001). 
47. Zheng, X. M. \& Ge, S. Ecological divergence in the presence of gene flow in two closely related Oryza species (Oryza rufipogon and O. nivara). Mol. Ecol. 19, 2439-2454 (2010).

48. Barbier, P., Morishima, H. \& Ishiharna, A. Phylogenetic relationship of annual and perennial wild rice: probing by direct DNA sequencing. Theor. Appl. Genet. 81, 693-702 (1991).

49. Lu, B. R., Zheng, K. L. \& Qian, H. R. Genetic differentiation of wild relatives of rice as assessed by RFLP analysis. Theor. Appl. Genet. 106, 101-106 (2002)

50. Zhu, Q. \& Ge, S. Phylogenetic relationships among A-genome species of the genus Oryza revealed by intron sequences of four nuclear genes. New Phytol. 167, 249-265 (2005).

51. Zhu, Q., Zheng, X., Luo, J., Gaut, B. S. \& Ge, S. Multilocus analysis of nucleotide variation of Oryza sativa and its wild relatives: severe bottleneck during domestication of rice. Mol. Biol. Evol. 24, 875-888 (2007).

52. Huang, X. et al. A map of rice genome variation reveals the origin of cultivated rice. Nature 490, 497-501 (2012).

53. Liu, R., Zheng, X. M., Zhou, L. \& Zhou, H. F. nd Ge, S. Population genetic structure of Oryza rufipogon and Oryza nivara: implications for the origin of O. nivara. Mol. Ecol. 24, 5211-5228 (2015).

54. Samal, R. et al. Morphological and molecular dissection of wild rices from eastern India suggests distinct speciation between $O$. rufipogon and O. nivara populations. Scientific reports 8, 1-13 (2018).

55. Melaku, G. et al. Genetic diversity and differentiation of the African wild rice (Oryza longistaminata chev. et roehr) in Ethiopia. Scientific African; https://doi.org/10.1016/j.sciaf.2019.e00138 (2019).

56. Zhang, Y. et al. Genome and comparative transcriptomics of African wild rice Oryza longistaminata provide insights into molecular mechanism of rhizomatousness and self-incompatibility. Molecular plant 8, 1683-1686 (2015).

57. He, R. et al. A systems-wide comparison of red rice (Oryza longistaminata) tissues identifies rhizome specific genes and proteins that are targets for cultivated rice improvement. BMC Plant Biology 14, 46 (2014).

58. Reuscher, S. et al. Assembling the genome of the African wild rice Oryza longistaminata by exploiting synteny in closely related Oryza species. Commun, Biol., https://doi.org/10.1038/s42003-018-0171-y (2018).

59. Ren, F., Lu, B. R., Li, S., Huang, J. \& Zhu, Y. A. comparative study of genetic relationships among the AA-genome Oryza species using RAPD and SSR markers. Theor. Appl. Genet. 108, 113-120 (2003).

60. Iwamoto, M., Nagashima, H., Nagamine, T., Higo, H. \& Higo, K. p-SINE1-like intron of the CatA catalase homologs and phylogenetic relationships among AA-genome Oryza and related species. Theor. Appl. Genet. 98, 853-861 (1999).

61. Cheng, C., Tsuchimoto, S., Ohtsubo, H. \& Ohtsubo, E. Evolutionary relationships among rice species with AA genome based on SINE insertion analysis. Genes Genet. Syst. 77, 323-334 (2002).

62. Wambugu, P. W., Brozynska, M., Furtado, A., Waters, D. L. \& Henry, R. J. Relationships of wild and domesticated rices (Oryza AA genome species) based upon whole chloroplast genome sequences. Scientific Reports 5, 13957, https://doi.org/10.1038/srep13957 (2015).

63. Cynthia, C. V., Linda, L. S. \& Kenneth, M. O. Long-term balancing selection at the Phosphorus Starvation Tolerance 1 (PSTOL1) locus in wild, domesticated and weedy rice (Oryza). BMC Plant Biol. 16, 101, https://doi.org/10.1186/s12870-016-0783-7 (2016).

64. Gao, L. Z. et al. Evolution of Oryza chloroplast genomes promoted adaptation to diverse ecological habitats. Commun. Boil. 2, 1-13 (2019).

65. Bao, Y. \& Ge, S. Origin and phylogeny of Oryza species with the CD genome based on multiple-gene sequence data. Plant Syst. Evol. 249, 55-66 (2004).

66. Wang, B. et al. Polyploid evolution in Oryza officinalis complex of the genus Oryza. BMC Evol. Biol. 9, 250, https://doi. org/10.1186/1471-2148-9-250 (2009)

67. Li, C., Zhang, D., Ge, S., Lu, B. \& Hong, D. Differentiation and inter-genomic relationships among C, E and D genomes in the Oryza officinalis complex (Poaceae) as revealed by multicolor genomic in situ hybridization. Theor. Appl. Genet. 103, 197-203 (2001).

68. Guo, Y. L. \& Ge, S. Molecular phylogeny of Oryzeae (Poaceae) based on DNA sequences from chloroplast, mitochondrial, and nuclear genomes. Am. J. Bot. 92, 1548-1558 (2005)

69. Hirsch, C. D., Wu, Y., Yan, H. \& Jiang, J. Lineage-specific adaptive evolution of the centromeric protein CENH3 in diploid and allotetraploid Oryza species. Mol. Biol. Evol. 26, 2877-2885 (2009).

70. Kumari, A. et al. Mining of rice blast resistance gene Pi54 shows effect of single nucleotide polymorphisms on phenotypic expression of the alleles. Eur. J. Pl. Pathol. 137, 55-65 (2013).

71. Li, H. J., Li, X. H., Xiao, J. H., Wing, R. A. \& Wang, S. P. Ortholog alleles at Xa3/Xa26 locus confer conserved race-specific resistance against Xanthomonas oryzae in rice. Molecular Plant 5, 281-290 (2012).

72. Hammond, S. M. et al. Human ADP-ribosylation factor-activated phosphatidylcholine-specific phospholipase D defines a new and highly conserved gene family. J. Biol. Chem. 270, 29640-29643 (1995).

73. Sung, T. et al. Mutagenesis of phospholipase D defines a superfamily including a trans-Golgi viral protein required for poxvirus pathogenicity. EMBO J. 16, 4519-4530 (1997).

74. Isshiki, M. et al. A naturally occuring funcional allele of the rice waxy locus has a GT to TT mutation at the 5 'splice site of the first intron. Plant J. 15, 133-138 (1998).

75. Nalefski, E. A. \& Falke, J. J. The C2 domain calcium-binding motif: structural and functional diversity. Protein Sci. 5, 2375-2390 (1996).

76. Perisic, O., Fong, S., Lynch, D. E., Bycroft, M. \& Williams, R. L. Crystal structures of a calcium-phospholipid binding domain from cytosolic phospholipase A2. J. Biol. Chem. 273, 1596-1604 (1998).

77. Pappan, K. \& Wang, X. Plant phospholipase $\mathrm{D} \alpha$ is an acidic phospholipase active at near-physiological $\mathrm{Ca}^{2+}$ concentrations. Arch. Biochem. Biophys. 368, 347-353 (1999).

78. Liscovitch, M., Czarny, M., Fiucci, G. \& Tang, X. Phospholipase D: molecular and cell biology of a novel gene family. Biochem. J. 345, 401-415 (2000)

79. Ponting, C. P. \& Perker, P. J. Extending the C2 domain family: C2s in PKCs delta, epsilon, eta, theta, phospholipases, GAPs, and perforin. Protein Sci. 5, 162-166 (1996)

80. Ryu, S. B. \& Wang, X. Activation of phospholipase D and the possible mechanism of activation in wound-induced lipid hydrolysis in castor bean leaves. Biochimica et. Biophysica Acta. 1303, 243-250.

81. Zheng, L., Krishnamoorthi, R., Zolkiewski, M. \& Wang, X. Distinct $\mathrm{Ca}^{2+}$ binding properties of novel C2 domains of plant phospholipase D $\alpha$ and $\beta$. J. Biol. Chem. 275, 19700-19706 (2000).

82. Croessmann, S. et al. PIK3CA C2 domain deletions hyperactivate phosphoinositide 3-kinase (PI3K), generate oncogene dependence, and are exquisitely sensitive to PI3Ko inhibitors. Clinical Cancer Research 24, 1426-1435 (2018).

83. McGee, J. D. et al. Rice phospholipase D isoforms show differential cellular location and gene induction. Plant Cell Physiol. 44, 1013-1026 (2003).

84. Janecek, S., Svensson, B. \& Henrissat, B. Domain evolution in the $\alpha$-amylase family. J. Mol. Evol. 45, 322-331 (1997).

85. MacGregor, E. A. $\alpha$-Amylase structure and activity. J. Protein Chem. 7, 399-415 (1988).

86. Ponting, C. P. \& Kerr, I. D. A novel family of phospholipase D homologues that include phospholipid synthases and putative endonucleases: identification of duplicated repeats and potential active site residues. Protein Sci. 5, 914-922 (1996).

87. Arhab, Y., Abousalham, A. \& Noiriel, A. Plant phospholipase D mining unravels new conserved residues important for catalytic activity. Biochimica et Biophysica Acta (BBA)-Molecular and Cell Biology of Lipids 1864, 688-703 (2019). 
88. Zheng, L., Shan, J., Krishnamoorthi, R. \& Wang, X. Activation of plant phospholipase D $\alpha$ by phosphatidylinositol 4 , 5-bisphosphate: characterization of binding site and mode of action. Biochemistry 41, 4546-4553 (2002).

89. Higashibata, A. et al. Decreased expression of myogenic transcription factors and myosin heavy chains in Caenorhabditis elegans muscles developed during space flight. J. Exp. Biol. 209, 3209-3218 (2006)

90. Woods, D. C., Alvarez, C. \& Johnson, A. L. Cisplatin-mediated sensitivity to TRAIL-induced cell death in human granulosa tumor cells. Gynecol. Oncol. 108, 632-640 (2008).

91. Paik, S. et al. A multigene assay to predict recurrence of tamoxifen-treated, node-negative breast cancer. N. Engl. J. Med. 351, $2817-2826$ (2004)

92. Larsson, P. K. A., Claesson, H. E. \& Kennedy, B. P. Multiple Splice Variants of the Human Calcium-independent Phospholipase $A_{2}$ and Their Effect on Enzyme Activity. J. Biol. Chem. 273, 207-214 (1998).

93. Campbell, M. A., Haas, B. J., Hamilton, J. P., Mount, S. M. \& Buell, C. R. Comprehensive analysis of alternative splicing in rice and comparative analyses with Arabidopsis. BMC genomics 7, 327 (2006).

94. Liu, J. et al. Alternative splicing of rice WRKY62 and WRKY76 transcription factor genes in pathogen defense. Plant Physiology 171, 1427-1442 (2016).

95. Ta, K. N. et al. Differences in meristem size and expression of branching genes are associated with variation in panicle phenotype in wild and domesticated African rice. EvoDevo; https://doi.org/10.1186/s13227-017-0065-y (2017).

96. Saghai-Maroof, M. A., Soliman, K. M., Jorgensen, R. A. \& Allard, R. W. Ribosomal DNA spacer length polymorphism in barley: Mendelian inheritance, chromosomal location and population dynamics. Proc. Nat. Acad. Sci., USA 81, 8014-8019 (1984)

97. Larkin, M. A. et al. Clustal W and Clustal X version 2.0. Bioinformatics 23, 2947-2948 (2007).

98. Sali, A. \& Blundell, T. L. Comparative protein modelling by satisfaction of spatial restraints. J. Mol. Biol. 234, 779-815 (1993).

99. Pettersen, E. F. et al. UCSF Chimera-a visualization system for exploratory research and analysis. J. Comput. Chem. 25, 1605-1612 (2004).

100. Kumar, S., Stecher, G. \& Tamura, K. MEGA7: Molecular Evolutionary Genetics Analysis Version 7.0 for Bigger Datasets. Mol. Biol. Evol. 33, 1870-1874 (2016).

101. Kaur, A. et al. Novel cis-acting regulatory elements in wild Oryza species impart improved rice bran quality by lowering the expression of Phospholipase D alphal enzyme (OsPLDa1). Mol. Biol. Rep. 47, 401-422 (2019).

102. Schmittgen, T. D. \& Livak, K. J. Analyzing real-time PCR data by the comparative $\mathrm{C}_{\mathrm{T}}$ method. Nature Protocols 3, 1101-1108 (2008).

\section{Acknowledgements}

The authors are thankful to the International Rice Research Institute (IRRI), Philippines, Manila and Central Rice Research Institute (CRRI), Cuttack, India for providing wild species germplasm of rice. This work was supported by the Monsanto's Beachell Borlaug International Scholarship Program, United States of America.

\section{Author contributions}

K.S. and B.G.D.R. designed the research and supervised experiments; A.K., K.K. and Ai. K. performed experiments; A.K. and K.N. analyzed data and wrote manuscript; all authors reviewed and approved the final manuscript.

\section{Competing interests}

The authors declare no competing interests.

\section{Additional information}

Supplementary information is available for this paper at https://doi.org/10.1038/s41598-020-62649-w.

Correspondence and requests for materials should be addressed to K.S.

Reprints and permissions information is available at www.nature.com/reprints.

Publisher's note Springer Nature remains neutral with regard to jurisdictional claims in published maps and institutional affiliations.

(c) (i) Open Access This article is licensed under a Creative Commons Attribution 4.0 International License, which permits use, sharing, adaptation, distribution and reproduction in any medium or format, as long as you give appropriate credit to the original author(s) and the source, provide a link to the Creative Commons license, and indicate if changes were made. The images or other third party material in this article are included in the article's Creative Commons license, unless indicated otherwise in a credit line to the material. If material is not included in the article's Creative Commons license and your intended use is not permitted by statutory regulation or exceeds the permitted use, you will need to obtain permission directly from the copyright holder. To view a copy of this license, visit http://creativecommons.org/licenses/by/4.0/.

(C) The Author(s) 2020 